\title{
Method for identifying drivers, barriers and synergies related to the deployment of a $\mathrm{CO}_{2}$ pipeline network A case study for the Iberian Peninsula and Morocco
}

\author{
Niels Berghout ${ }^{\mathrm{a}, *}$, Helena Cabal ${ }^{\mathrm{b}}$, João Pedro Gouveia ${ }^{\mathrm{c}}$, Machteld van den Broek ${ }^{\mathrm{a}}$, \\ André Faaij ${ }^{\mathrm{d}}$ \\ ${ }^{a}$ Copernicus Institute of Sustainable Development, Energy \& Resources, Faculty of Geosciences, Utrecht University, The Netherland \\ b Spanish National Research Centre for Energy, Environment and Technology (CIEMAT), Spain \\ ${ }^{c}$ Center for Environmental and Sustainability Research (CENSE), Faculty of Science and Technology, Universidade Nova de Lisboa, Portugal \\ ${ }^{\mathrm{d}}$ Energy Academy Europe, University of Groningen, Groningen, The Netherlands. Energy \& Sustainability Research Institute Groningen, Groningen, The \\ Netherlands
}

\section{A R T I C L E I N F O}

\section{Article history:}

Received 28 January 2015

Received in revised form 19 May 2015

Accepted 21 May 2015

Available online 24 July 2015

\section{Keywords:}

CCS

Pipeline

Transport

Infrastructure

Barriers

Case study

\begin{abstract}
A B S T R A C T
This paper provides a method to identify drivers, barriers and synergies (DBS) related to the deployment of a $\mathrm{CO}_{2}$ pipeline network. The method was demonstrated for the West Mediterranean region (WMR) (i.e. Spain, Portugal and Morocco). The method comprises a literature review, analysis of embedded pipeline trajectories, interviews with experts, and workshops with stakeholders. Subsequently, the collected information was used to identify route specific DBS in several $\mathrm{CO}_{2}$ pipeline network deployment scenarios that were modeled for the WMR. Most identified DBS apply to $\mathrm{CO}_{2}$ pipeline transport in general. The barriers (e.g. technical knowledge gaps, outstanding legislative issues, lack of financial incentive) can in principle be tackled to make the design, construction and operation of a $\mathrm{CO}_{2}$ pipeline network possible, but could sometimes lead to somewhat higher costs. Furthermore, there are also facilitating processes (e.g. experience with $\mathrm{CO}_{2}$ pipeline transport for $\mathrm{EOR}$ ). Cost benefits due to pipeline oversizing were identified as a route specific driver, whereas crossings of mountains, water and nature areas are route specific barriers. Installing $\mathrm{CO}_{2}$ pipelines along natural gas pipelines could be either a route specific synergy or barrier, depending on site conditions. Finally, several key measures were proposed to enable $\mathrm{CO}_{2}$ pipeline networks in the future.
\end{abstract}

(c) 2015 Elsevier Ltd. All rights reserved.

\section{Introduction}

$\mathrm{CO}_{2}$ capture and storage (CCS) can play a key role in a portfolio of greenhouse gas emission (GHG) reduction options needed to achieve the stabilization target of $450 \mathrm{ppm}(\mathrm{v}) \mathrm{CO}_{2}$-equivalent (IEA, 2012). A key condition to the worldwide proliferation of CCS is the development of large-scale transport networks, which will form

Abbreviations: CCS, carbon capture and storage; CFS, cross-frontier scenario; CS, conservative CCS scenario; DBS, drivers, barriers and synergies; EOR, enhanced oil recovery; ETS, emission trading scheme; FRS, free-routes scenario; GDP, gross domestic production; GHG, greenhouse gas; GIS, geographical information system; $\mathrm{GTP}, \mathrm{CO}_{2}$ pipeline transport in general; IEA, international energy agency; MOP, multiple oil products; PIG, pipeline inspection gauge; $p p m(v)$, parts per million (by volume); PPP, public private partnership; ROW, right of way; SPT, specific $\mathrm{CO}_{2}$ pipeline transport; $t$, metric tonne; WMR, West Mediterranean region.

* Corresponding author.

E-mail address: n.a.berghout@uu.nl (N. Berghout). the essential link between the carbon capture and storage step. First estimations of the International Energy Agency (IEA, 2010) indicated that extensive worldwide pipeline networks of between 200,000 and $550,000 \mathrm{~km}$ would be required, depending on the configurations of the networks, to avoid approximately $8.2 \mathrm{GtCO}_{2}$ in 2050 , which is around $19 \%$ of the necessary reduction worldwide (Knoope et al., 2013). The large-scale deployment of pipeline networks as envisioned by the IEA requires timely and stable action (GCCSI, 2012). Region-specific roadmaps are needed to deal successfully with all aspects of $\mathrm{CO}_{2}$ network development, including measures to remove potential barriers related to pipeline technology, legislation, policy, economics, finance and organization, which could hamper the deployment of pipeline infrastructures (Element Energy Limited, 2010a; GCCSI, 2012). In addition, efforts should be made to exploit the existing experience and knowledge base accumulated with conventional pipeline transport and CCS demonstration projects, which could drive and expedite the development of $\mathrm{CO}_{2}$ pipeline networks. A comprehensive overview of relevant 
and important drivers, barriers and synergies (DBS) is, therefore, desirable to serve as input for region-specific roadmaps.

Several studies aimed to identify DBS related to $\mathrm{CO}_{2}$ transport infrastructures. These studies are mainly based on literature reviews and desktop research (e.g. ICF International, 2009; Insight Economics, 2011; Wu and Ramírez, 2010). Some analyses also included interviews with stakeholders to gauge their views on various aspects of a potential CCS network (e.g. ICF International, 2009; Mikunda et al., 2011b), studies of pipeline trajectories transporting hydrocarbons or other substances to draw lessons from other pipeline industries ${ }^{1}$ (NERA Economic Consulting, 2009a,b), or both (Chrysostomidis and Zakkour, 2008). Research carried out by Element Energy Limited (2010b,c) comprised workshops with groups of stakeholders, but excluded the analysis of analogue pipeline trajectories. Whereas some of these studies (e.g. Element Energy Limited, 2010b) covered multiple aspects (i.c. technology, legislation, policy, economics, finance and organization) of $\mathrm{CO}_{2}$ pipeline networks, most studies (e.g. DECC, 2010; ICF International, 2009) focused on merely one or two aspects (i.c. technology and legislation). In addition, nearly all referenced studies originate from industry. To the authors' knowledge, a comprehensive and consistent, yet thorough method, including all the aforementioned data collection methods and covering all relevant aspects, to identify the DBS for a regional pipeline network is currently not available in the scientific literature.

The main objective of this paper is, therefore, to provide a method for the DBS related to the deployment of a regional $\mathrm{CO}_{2}$ pipeline network. The DBS cover the aspects of technology, legislation/policy, economics/finance and organization. Although relevant, the aspect of public perception was excluded from the analysis as the topic was too broad for the scope of this study. In this paper, the West Mediterranean region (WMR) (i.e. Spain, Portugal and Morocco) was selected as a case study to demonstrate the method. Such an inventory has hitherto not been carried out for this region. In the COMET project, the potential role of CCS in the WMR as well as several possible $\mathrm{CO}_{2}$ pipeline networks have been modelled (Gouveia et al., 2013; Kanudia et al., 2013, 2012a,b,c; Van den Broek et al., 2013b) (see Section 2). The results showed that CCS can play an important role in the WMR to achieve deep $\mathrm{CO}_{2}$ emission reductions. Moreover, the WMR is a suitable region for CCS considering its large $\mathrm{CO}_{2}$ storage capacity, mainly in the form of saline aquifers, but also oil and gas fields (Martínez and Carneiro, 2011). If CCS will take off on a large scale, the Iberian Peninsula (and Morocco) will likely form its own integrated $\mathrm{CO}_{2}$ pipeline network with no connections to central and northwest Europe, due to the large distances involved and the mountain ranges in between (Mikunda et al., 2011b; Van den Broek et al., 2013a). Furthermore, the heterogeneity among the countries in terms of economic development and legal framework (EU vs. non-EU) could possibly result in the identification of drivers, barriers and synergies (DBS) that are currently still unknown. In addition to generic DBS, this paper aims to identify and assess specific DBS related to the $\mathrm{CO}_{2}$ pipeline network configurations and deployment pathways modelled in the COMET project.

\footnotetext{
1 Several studies (e.g. NERA Economic Consulting, 2009a,b) draw an analogy between pipelines carrying anthropogenic $\mathrm{CO} 2$ and pipelines carrying other substances (mainly natural gas) due to the large overlap in design, construction and operation practices, which allows for the identification of DBS related to $\mathrm{CO}_{2}$ pipelines. In this study, existing pipeline trajectories from which lessons are drawn for future $\mathrm{CO}_{2}$ pipelines are referred to as 'analogue pipeline trajectories'.2This paper and cited research were conducted within the context of the COMET project, which aimed to identify and assess the most cost effective $\mathrm{CO}_{2}$ transport and storage infrastructure able to serve the WMR. The COMET project was funded by the EU.
}

\section{Methods}

This section presents the method to identify the DBS related to the deployment of a $\mathrm{CO}_{2}$ pipeline network (Section 2.1). The case study and data collection are discussed in Section 2.2.

\subsection{Approach}

Prior to this analysis, a model was designed to simulate $\mathrm{CO}_{2}$ pipeline network deployment scenarios for the WMR (see Kanudia et al., 2013, 2012a,b,c; Van den Broek et al., 2013b). These deployment scenarios were used to identify the specific DBS, hereafter referred to as route specific DBS, related to the $\mathrm{CO}_{2}$ pipeline networks across the WMR. Although this modeling step is not part of this paper, a short description of the model is given in Section 2.1.1 to create a better understanding of the simulated pipeline networks. Next, definitions are given for the DBS (Section 2.1.2). The scoring procedure, data collection and the procedure for the identification of the route specific DBS are described in Sections 2.1.3-2.1.5, respectively.

\subsubsection{COMET model}

The tailor-made COMET model was designed using a system analytical approach based on bottom-up techno-economic models generated by the MARKAL-TIMES software and geographical information system (GIS). The approach was chosen to integrate spatial, temporal, and techno-economic aspects to determine the role of CCS in the energy system and the development of the CCS infrastructure. Multiple scenarios were built, each with different assumptions on inter alia Gross Domestic Production (GDP) growth and concomitant $\mathrm{CO}_{2}$ emissions. Based on these scenarios, several potential $\mathrm{CO}_{2}$ pipeline networks were simulated. More information on the model can be found in Kanudia et al. 2013, 2012a,b,c).

\subsubsection{Definitions}

The DBS are categorized into four themes: technology, legislation/policy, economics/finance and organization. In this study, a driver is defined as a factor that enhances the design, construction and operation of $\mathrm{CO}_{2}$ pipeline networks. A synergy is a situation in which benefits can be attained by combining two or more processes. A barrier is defined as a factor that impedes or delays the design, construction and operation of $\mathrm{CO}_{2}$ pipeline networks. In this study, the terms driver, barrier and synergy can refer to present DBS (e.g. current low $\mathrm{CO}_{2}$ price) or to (potential) DBS in the future (e.g. sub-optimal buildout of a large-scale $\mathrm{CO}_{2}$ pipeline network). Table 1 presents examples of the DBS for each theme to clarify the concepts.

\subsubsection{Scoring procedure}

The data collection was divided into an international literature review and information collection at the national country level. The scoring procedure is shown schematically in Fig. 1. The DBS that were identified in international literature or in a particular country were indicated with a tick $(\sqrt{ })$. In case the DBS were not identified by a local stakeholder and/or project partner, but was after discussion with local stakeholders confirmed or expected to apply to this particular country as well, they were indicated with a plus (+). In case they were considered not to apply to this country, they were indicated with a minus ( - ). A question mark (?) was used to indicate that it was unknown whether the DBS apply to a particular country. The score 'not identified' applies to DBS that were identified in one or more of the three studied countries, but not in the international literature. 
Table 1

Examples of drivers, synergies and barriers reported in literature.

\begin{tabular}{|c|c|c|}
\hline & Examples & Reference \\
\hline \multicolumn{3}{|c|}{ TECHNOLOGY } \\
\hline Driver $^{\mathrm{a}}$ & $\begin{array}{l}\text { Technical knowledge/experience with hydrocarbon pipeline } \\
\text { construction/operation }\end{array}$ & European Union (2012), Insight Economics (2011) \\
\hline Barrier & Knowledge gaps on the corrosion effect of the impurities in $\mathrm{CO}_{2}$ streams. & Ramírez et al. (2011) \\
\hline \multicolumn{3}{|c|}{ LEGISLATION/POLICY } \\
\hline Driver $^{\mathrm{a}}$ & $\begin{array}{l}\text { Existing legislation and experience with legal procedures related to } \\
\text { (conventional or } \mathrm{CO}_{2} \text { ) pipeline transport and pipeline projects }\end{array}$ & Element Energy Limited (2010a), SSEB (2010) \\
\hline Barrier & $\begin{array}{l}\text { Inconsistency in countries' jurisdictions on technical standards of } \mathrm{CO}_{2} \text { pipeline } \\
\text { construction, operation and } \mathrm{CO}_{2} \text { flows }\end{array}$ & Insight Economics (2011) \\
\hline \multicolumn{3}{|c|}{ ECONOMICS/FINANCE } \\
\hline Driver $^{\mathrm{a}}$ & $\begin{array}{l}\text { Re-use of captured } \mathrm{CO}_{2} \text { in other markets (e.g. chemicals, biofuels, greenhouses, } \\
\text { etc.) }\end{array}$ & Chrysostomidis and Zakkour (2008), Insight Economics (2011) \\
\hline Synergy & Re-use of existing pipelines & Insight Economics (2011) \\
\hline Barrier & Lack of economic incentives (e.g. $\mathrm{CO}_{2}$ price) & Chrysostomidis and Zakkour (2008), Sanders et al. (2013) \\
\hline \multicolumn{3}{|c|}{ ORGANIZATION } \\
\hline Driver $^{\mathrm{a}}$ & Experience with organizational models of natural gas pipeline projects & Mikunda et al. (2011), SSEB (2010), Wu and Ramírez (2010) \\
\hline Barrier & Knowledge gap on planning and organization of future $\mathrm{CO}_{2}$ pipeline networks & Element Energy Limited (2010c) \\
\hline
\end{tabular}

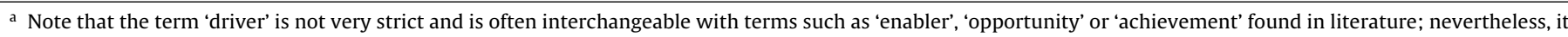
was decided to adhere to the term 'driver' throughout this study for the sake of consistency and clarity.

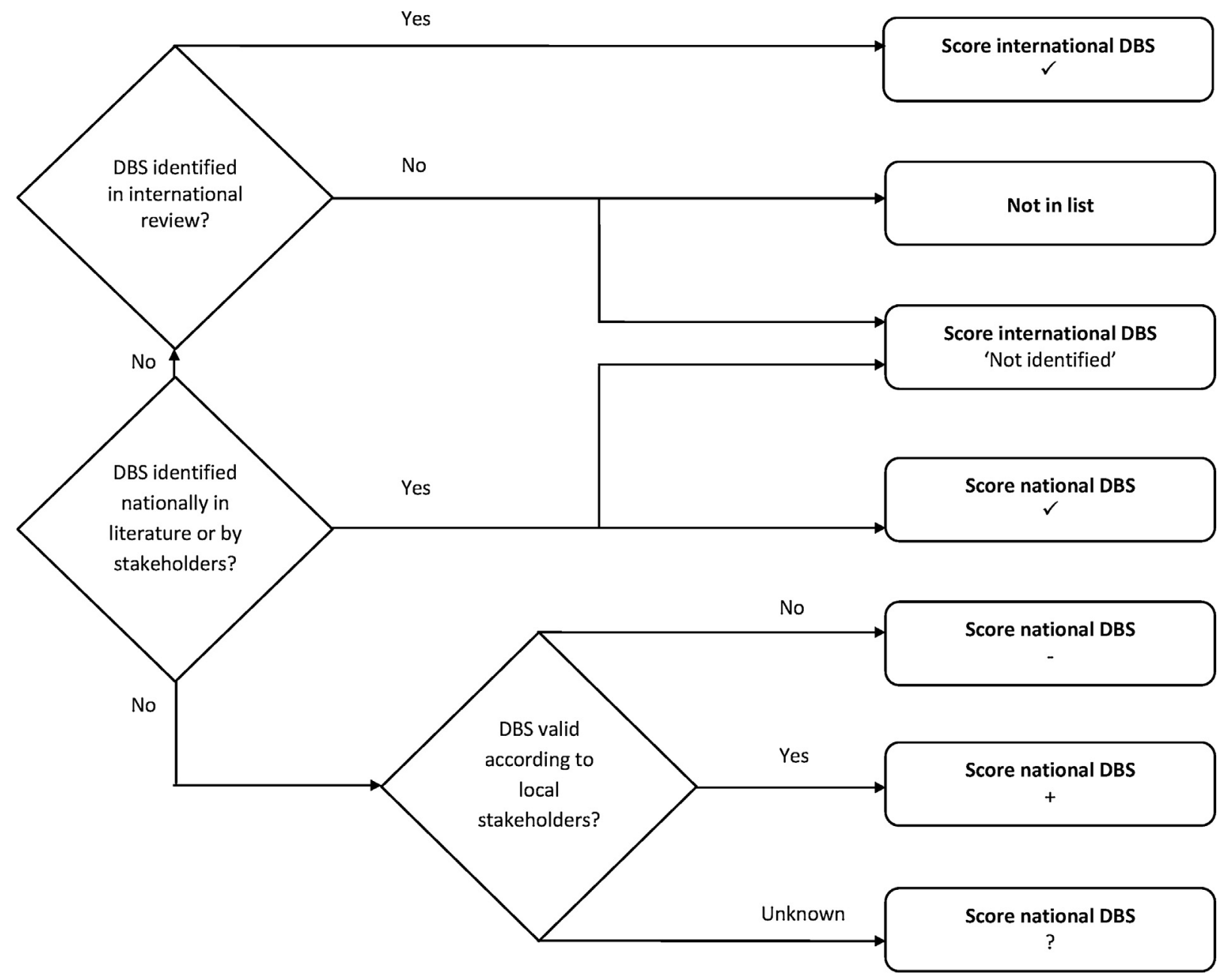

Fig. 1. Hierarchy for assigning scores to the drivers, barriers and synergies.

\subsubsection{Data collection}

The data collection comprised the following consecutive steps:

- An inventory of international literature to obtain an up-to-date overview of available knowledge on DBS related to the design, construction and operation of $\mathrm{CO}_{2}$ pipeline networks. The review covered studies from both academia and industry, with varying geographical scopes (country, regional and global level), and with a focus on the technological, legislative, political, economic, financial or organizational aspects of $\mathrm{CO}_{2}$ pipelines or pipeline networks. 
- An inventory of national literature comprising official policy and legal documents on (hydrocarbon) pipeline design, construction and operation, academic publications written in the local language, and if available, reports on local CCS projects. These sources provide information on, among others, embedded legislation, technical standards, routing, and organization of pipeline networks.

- Studying analogue pipeline trajectories (e.g. carrying hydrocarbons, water or $\mathrm{CO}_{2}$ ) to provide new insight on DBS of pipelines. This step concerns mainly the collection of publicly available information.

- Interviews with stakeholders and experts involved in the design, construction and operation of the analogue pipeline trajectories to fill in remaining knowledge gaps and allow for a better understanding of important pipeline issues and solutions. Furthermore, the experts were asked about their expectations regarding future $\mathrm{CO}_{2}$ pipelines in order to validate and complement the DBS identified in literature.

- Workshops with potential future stakeholders (e.g. energy and pipeline companies, government institutes) were organized in each of the countries under study. The aim of the workshops was to exchange information, ideas and visions on the preconditions of future $\mathrm{CO}_{2}$ pipeline networks. Stakeholders were encouraged to ask questions, provide feedback and give information on the presented DBS.

\subsubsection{Analysis of DBS of chosen infrastructure options}

The results from the data collection and $\mathrm{CO}_{2}$ pipeline networks were combined to identify route specific DBS. Whereas some DBS are rather generic (e.g. related to finance), several DBS can be related to the specific model results, such as oversizing of particular trunk $\mathrm{CO}_{2}$ pipelines. The route specific DBS were identified for the pipeline network under several scenarios. Also, the uncertainty in the model results and its impact on the DBS are discussed.

\subsection{Case study: Iberian Peninsula and Morocco}

\subsubsection{West Mediterranean region}

Three $\mathrm{CO}_{2}$ pipeline network scenarios were modelled for the WMR that differed with respect to: (1) whether $\mathrm{CO}_{2}$ pipelines should follow existing pipelines (mainly natural gas) where available (Conservative CCS and Cross-frontier scenario), or not (Free-routes scenario), and (2) on the possibility to transport $\mathrm{CO}_{2}$ across national borders (Cross-frontier scenario) or to restrict $\mathrm{CO}_{2}$ transport to the country level (Conservative CCS and Free-routes scenarios) (see Figs. 2-4). The pipeline network scenarios apply to the year 2030. Further information on the WMR case study and the three pipeline network scenarios can be found in Appendix A.

\subsubsection{Data collection}

An overview of the main international literature sources published over the period 2008-2012 is presented in Table 3. Studies published before 2008 were excluded from the inventory as they may contain outdated information on, for example, legislative issues.

Data on the national natural gas network were taken from government agencies (AICEP, 2008; CNE, 2013a,b), (EDP, 2009; REN, 2013), environmental impact assessments (Agripo Ambiente, 1995; Compostilla Project, 2013; Hidroprojecto, 2001; IMPACTE, 1997, 1996; Mikunda et al., 2011b; Ren, 2007; SEIA, 1995a,b, 1994), and academia (Relvas, 2008; Santos, 2011). Information on legislation was mainly taken from ERM Iberia (2004), Pöyry/Heymo (2011), Ren Gasodutos (2007).

Seven analogue pipeline trajectories were studied (see Table 2 and Fig. 5). The pipeline trajectories differ with respect to route, transported matter, length, and underground (onshore vs. offshore). Experts within the organizations involved in the analogue pipeline projects (Galp Energia; REN S.A.; CLC, Companhia Logística de Combustíveis; ENDESA; ENAGÁS) were contacted to collect additional information and make use of their knowledge, experience and expectations on $\mathrm{CO}_{2}$ pipelines. An overview of the key technical features of the analogue pipeline trajectories can be found in Appendix B.

Several interviews were held with experts from companies. In Spain, a meeting was organized with the Spanish natural gas transport company ENAGÁS and the Spanish energy company ENDESA. The latter has also participated in the COMET project as industry partner contributing with its experience and knowledge based on OXY-300-CFB project in Compostilla. In Portugal, two meetings took place, one with two experts from REN Gasodutos S.A. (national natural gas transportation operator) and one meeting with Galp Energia and CLC (a group of Portuguese companies engaged in inter alia natural gas transport). In the results section, the interviews with Galp Energia, REN Gasodutos S.A., and ENDESA/ENAGÁS are referred to as interview 1,2 and 3, respectively; detailed accounts of the interviews can be found in COMET (2012a), COMET (2012b) and COMET (2012c), respectively.

The workshops with local stakeholders (energy and pipeline companies, government institutes, industry, universities, and other organizations) were held in Marrakesh (1), Lisbon (2) and Madrid

Table 2

Analogue pipeline trajectories.

\begin{tabular}{|c|c|c|c|c|c|}
\hline & Route & Transported matter & On-/offshore & Length $(\mathrm{km})$ & Start year operation \\
\hline $\mathrm{I}^{\mathrm{a}}$ & Sines-Setubal (Portugal) & Natural gas & Onshore & 87 & 2003 \\
\hline $\mathrm{II}^{\mathrm{b}}$ & Setubal-Braga (Portugal) & Natural gas & Onshore & 580 & 1997 \\
\hline III $^{\mathrm{C}}$ & Braga (Portugal)-Tuy (Spain) & Natural gas & Onshore & 76 & 1997 \\
\hline $\mathrm{IV}^{\mathrm{d}}$ & Sines-Aveiras de Cima (Portugal) & M.O.P. ${ }^{\mathrm{h}}$ & Onshore & 147 & 1996 \\
\hline $\mathrm{V}^{\mathrm{e}}$ & Campo Maior-Leiria (Portugal) & Natural gas & Onshore & 220 & 1997 \\
\hline $\mathrm{VI}^{\mathrm{f}}$ & Medgaz: Beni Saf (Algeria)-Almeria (Spain) & Natural gas & On-/offshore & 210 & 2008 \\
\hline $\mathrm{VII}^{\mathrm{g}}$ & Compostilla-Santa María del Monte de Cea (Spain) & $\mathrm{CO}_{2}$ & Onshore & 140 & Canceled $^{\mathrm{i}}$ \\
\hline
\end{tabular}

a Hidroprojecto (2001).

b $\operatorname{SEIA}(1995 a, b, 1994)$

c IMPACTE $(1997,1996)$.

d Agripo Ambiente (1995).

e $\operatorname{REN}$ (2007).

f Mikunda et al. (2011b).

g Compostilla Project (2013).

h Multiple Oil Products

i The Spanish energy company ENDESA was awarded European Commission funding by the end of 2009 for the CCS Compostilla Project. The project involved the construction

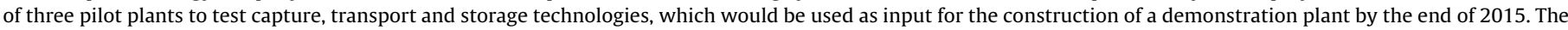

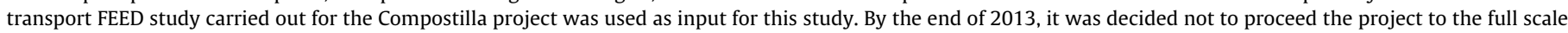
demonstration stage (Foster Wheeler, 2013; GCCSI, 2014). 


\section{Conservative CCS 2030}

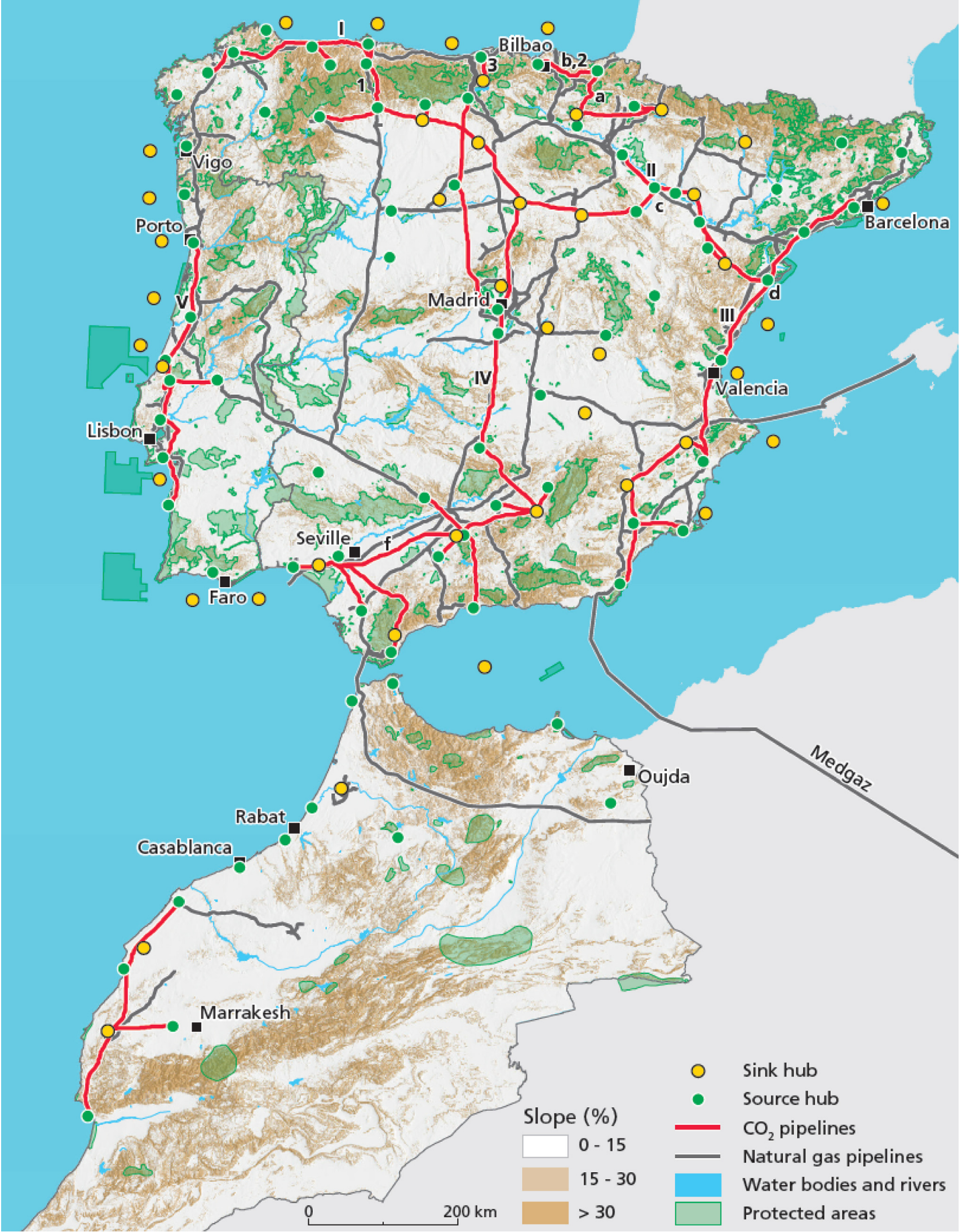

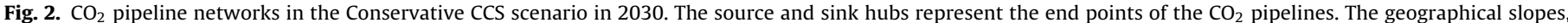

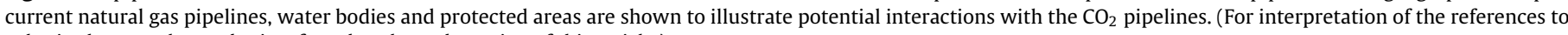
color in the text, the reader is referred to the web version of this article.) 


\section{Cross-frontier 2030}

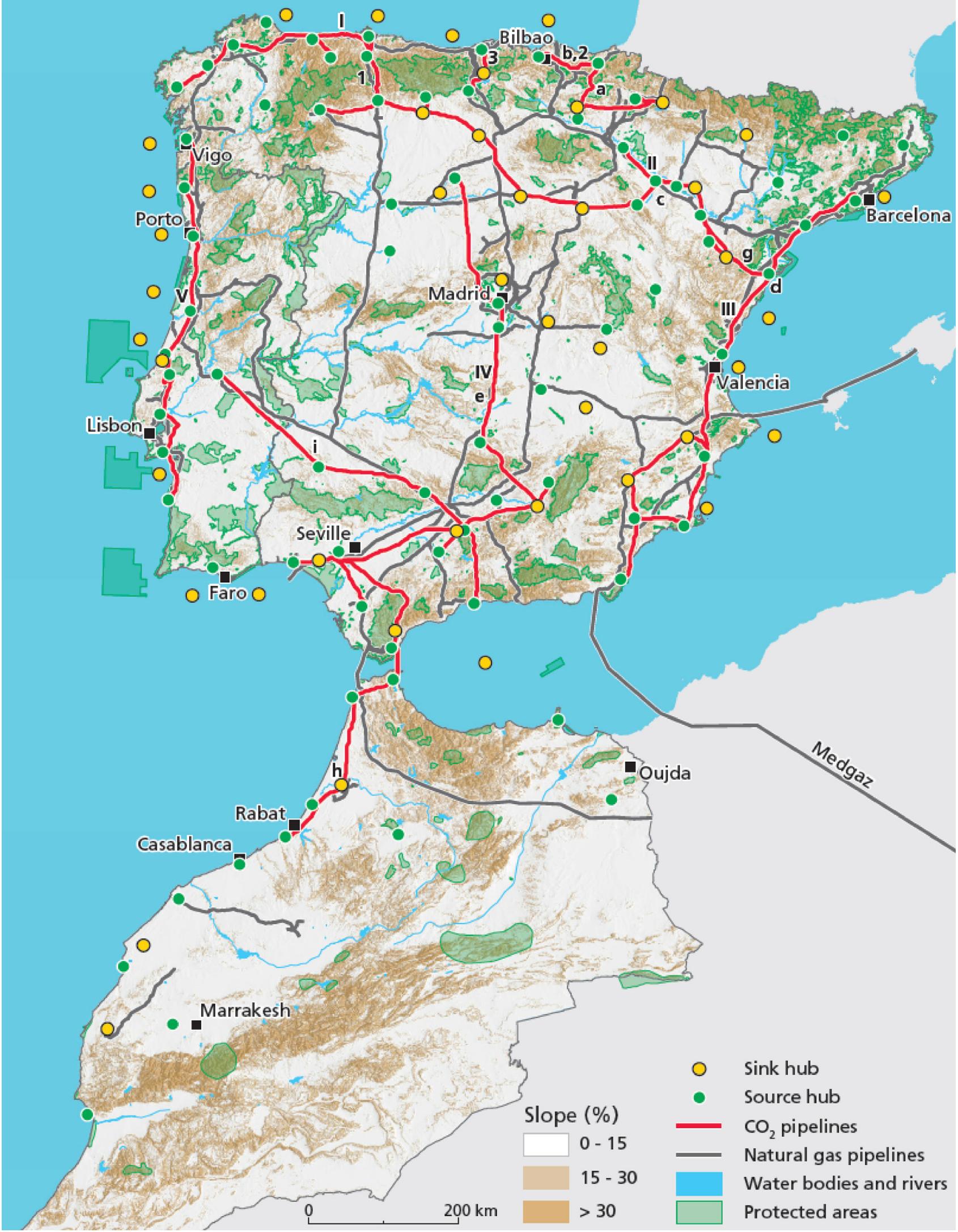

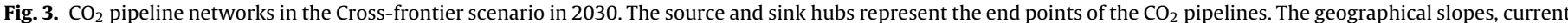

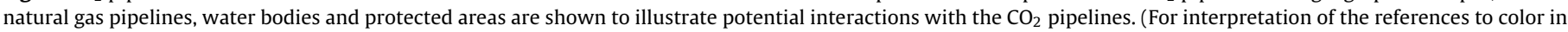
the text, the reader is referred to the web version of this article.) 


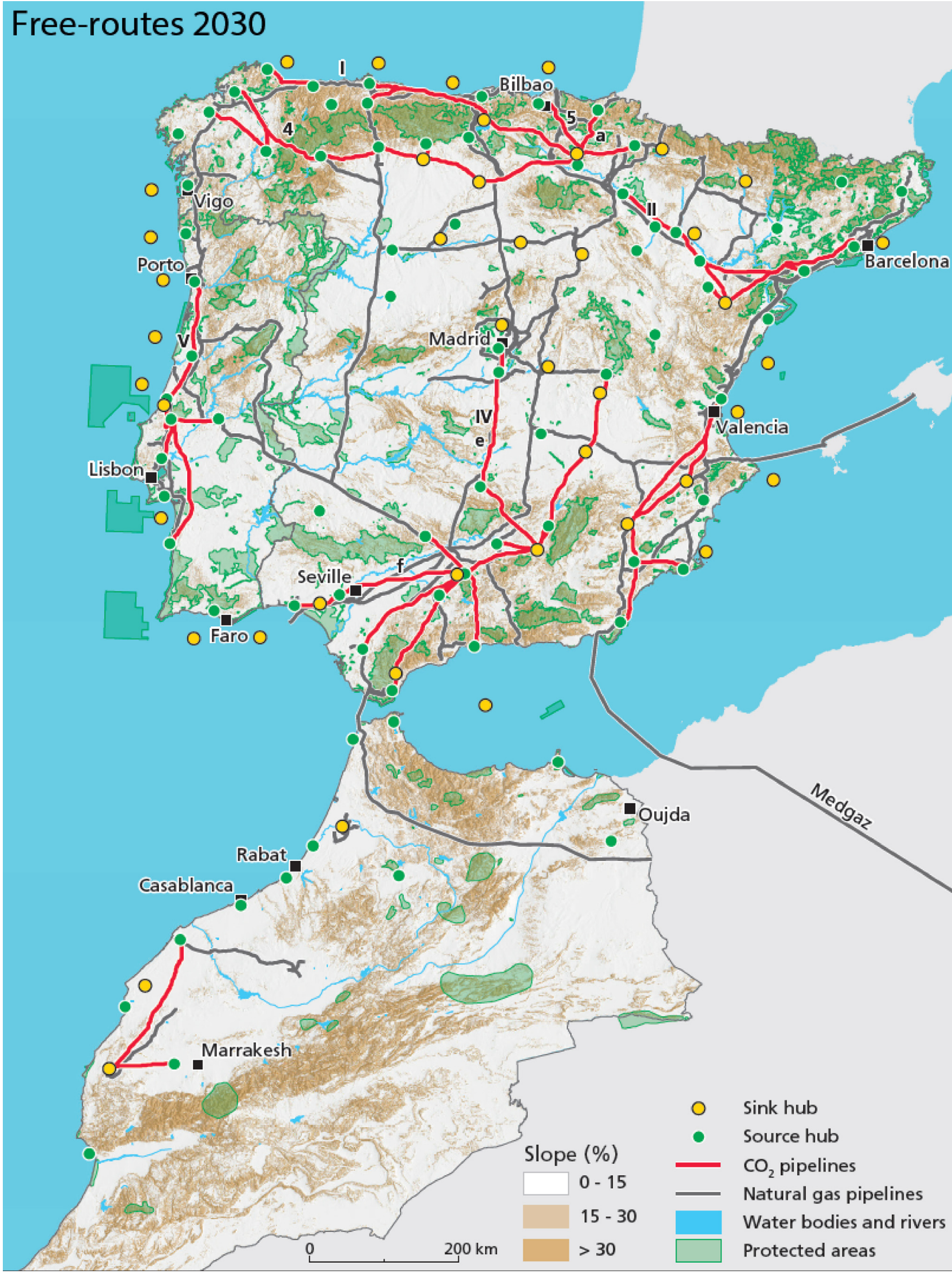

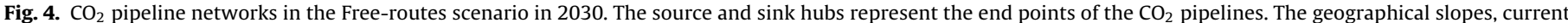

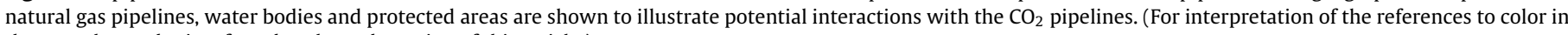
the text, the reader is referred to the web version of this article.) 


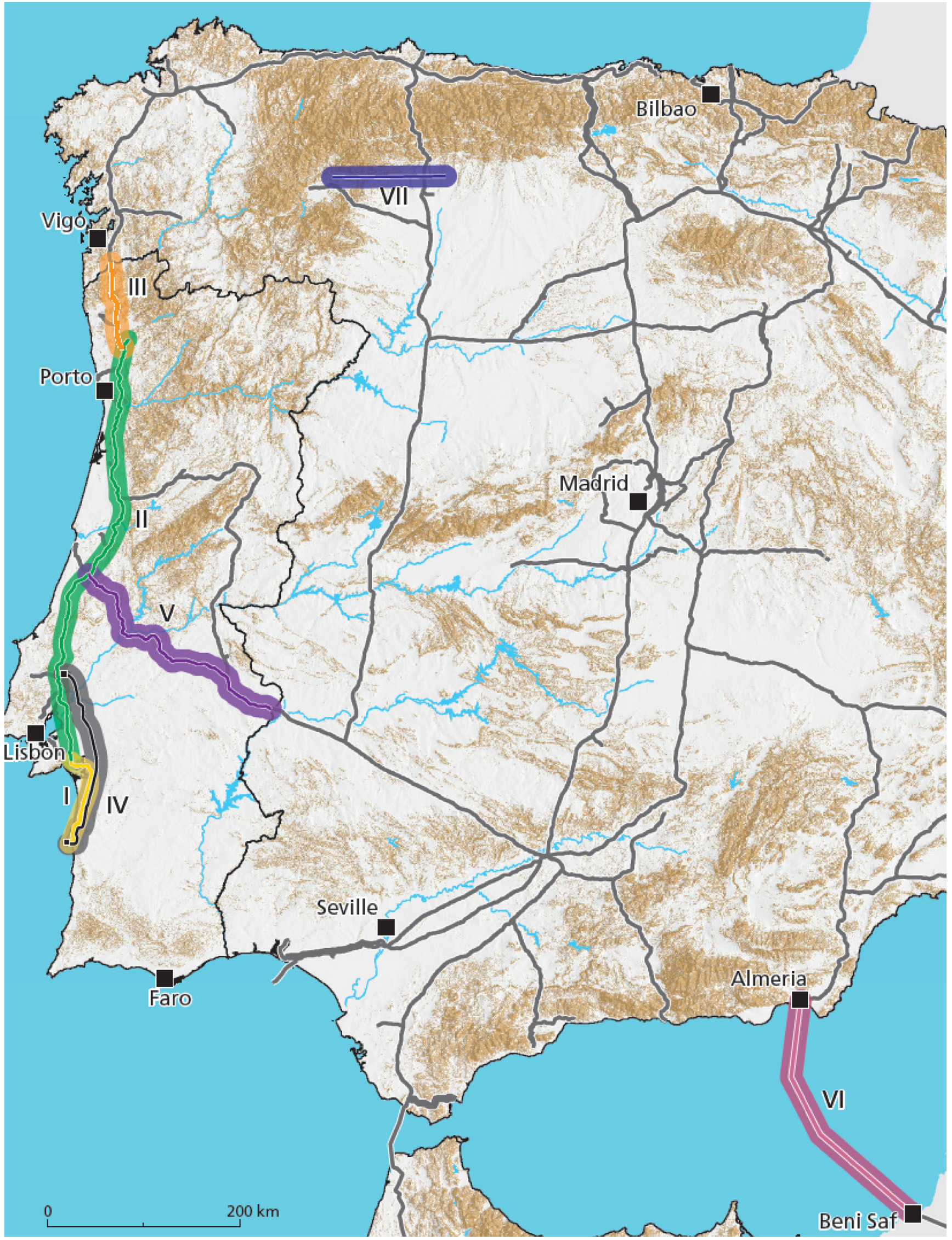

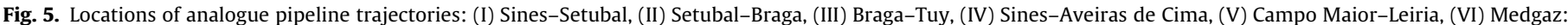

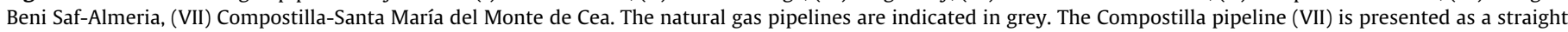
line as the exact pipeline route is unknown. 
Table 3

Overview of international literature on $\mathrm{CO}_{2}$ pipeline transport (2008-2012) used for the inventory.

\begin{tabular}{|c|c|c|c|c|c|c|c|c|c|}
\hline \multirow[t]{2}{*}{ Study } & \multirow[t]{2}{*}{ Geographical Scope } & \multicolumn{4}{|c|}{ Aspects covered } & \multicolumn{4}{|l|}{ Method } \\
\hline & & Technology & $\begin{array}{l}\text { Policy/ } \\
\text { legislation }\end{array}$ & $\begin{array}{l}\text { Economics/ } \\
\text { finance }\end{array}$ & Organization & Desktop research & $\begin{array}{l}\text { Analogue pipeline } \\
\text { trajectories }\end{array}$ & $\begin{array}{l}\text { Interviews with } \\
\text { stakeholders }\end{array}$ & Workshops \\
\hline Chrysostomidis and Zakkour (2008) & Worldwide & & $\sqrt{ }$ & $\sqrt{ }$ & $\sqrt{ }$ & $\sqrt{ }$ & $\sqrt{ }{ }^{a}$ & $\sqrt{ }{ }^{a}$ & \\
\hline ICF International (2009) & USA; Canada & $\sqrt{ }$ & $\sqrt{ }$ & & & $\sqrt{ }$ & & $\sqrt{b}$ & \\
\hline NERA Economic Consulting (2009a,b) & UK & & $\sqrt{ }$ & $\sqrt{ }$ & $\sqrt{ }$ & $\sqrt{ }$ & $\sqrt{ }^{\mathrm{c}}$ & & \\
\hline Koornneef et al. (2010) & Worldwide & $\sqrt{ }$ & & & & $\sqrt{ }$ & & & \\
\hline Wu and Ramírez (2010) & $\begin{array}{l}\text { Norway, UK, Denmark, } \\
\text { Germany and the Netherlands }\end{array}$ & & $\sqrt{ }$ & $\sqrt{ }$ & $\sqrt{ }$ & $\sqrt{ }$ & & & \\
\hline Element Energy Limited, 2010b & $\begin{array}{l}\text { Netherlands, Germany, } \\
\text { Norway and the UK }\end{array}$ & & $\sqrt{ }$ & & & $\sqrt{ }$ & $\sqrt{ }^{\mathrm{d}}$ & $\sqrt{ }^{\mathrm{d}}$ & $\sqrt{ }^{\mathrm{d}}$ \\
\hline Element Energy Limited (2010a) & Worldwide & $\sqrt{ }$ & $\sqrt{ }$ & $\sqrt{ }$ & & $\sqrt{ }$ & & & \\
\hline SSEB (2010) & USA & & $\sqrt{ }$ & $\sqrt{ }$ & $\sqrt{ }$ & $\sqrt{ }^{\mathrm{e}}$ & & $\sqrt{ }^{\mathrm{e}}$ & \\
\hline $\operatorname{DECC}(2010)$ & UK & & $\sqrt{ }$ & $\sqrt{ }$ & & $\sqrt{ }$ & & & \\
\hline Element Energy Limited (2010c) & UK & $\sqrt{ }$ & $\sqrt{ }$ & $\sqrt{ }$ & $\sqrt{ }$ & $\sqrt{ }$ & & $\sqrt{ }^{\mathrm{f}}$ & $\sqrt{ }^{\mathrm{f}}$ \\
\hline Insight Economics (2011) & Worldwide & $\sqrt{ }$ & $\sqrt{ }$ & & & $\sqrt{ }$ & & & \\
\hline Mikunda et al. (2011b) & Europe & & $\sqrt{ }$ & & $\sqrt{ }$ & $\sqrt{ }$ & & $\mathfrak{J}^{\mathrm{g}}$ & $\mathfrak{J}^{\mathrm{g}}$ \\
\hline IEA (2011) & $\begin{array}{l}\text { London Protocol contracting } \\
\text { parties }\end{array}$ & & $\sqrt{ }$ & & & $\sqrt{ }$ & & & \\
\hline Mikunda et al. (2011a) & Mainly the Netherlands & & $\sqrt{ }$ & $\sqrt{ }$ & & $\sqrt{ }$ & $\sqrt{ }^{\mathrm{h}}$ & & \\
\hline European Union (2012) & Denmark, Norway, Sweden & & $\sqrt{ }$ & & & $\sqrt{ }$ & & & \\
\hline
\end{tabular}

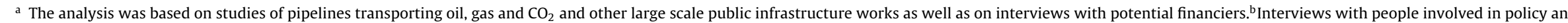

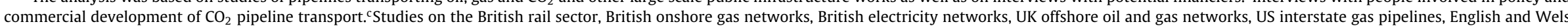

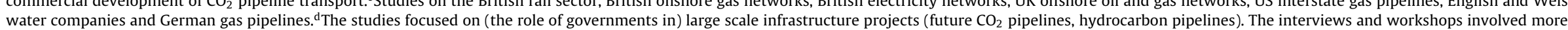

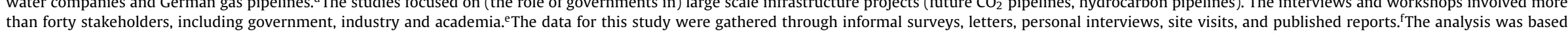

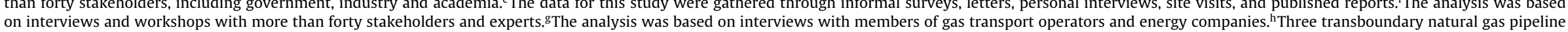
on interviews and wolkshops with gevere trajectories were examined to identify legal issues. 
(3). An overview of the stakeholders who attended the workshops can be found in Appendix C. In the results section, the workshops are referred to as workshop 1,2 and 3; a detailed account of the workshops can be found in Boavida et al. (2012b).

\section{Results}

The DBS related to technology, legislation/policy, economics/finance and organization are presented in sections 3.1-3.4, respectively. Each section is divided into two subsections: drivers and synergies (1) and barriers (2). We ordered the DBS roughly from DBS with a potentially higher impact to lower impact. The findings include both DBS related to CCS in general and for $\mathrm{CO}_{2}$ pipeline transport in particular. The latter can be divided into DBS related to $\mathrm{CO}_{2}$ pipeline transport in general and for the specific pipeline routes in the model scenarios. The last group of DBS is further discussed in Section 3.5. The type of DBS is also indicated in the overview tables in each section.

\subsection{Technology}

An overview of the technological DBS is presented in Table 4.

\subsubsection{Drivers and synergies}

- There is long worldwide experience with the design, construction and operation of both on- and offshore (high pressure) pipeline networks carrying natural gas and oil (Element Energy Limited, 2010a; European Union, 2012; Insight Economics, 2011), which could drive the deployment of $\mathrm{CO}_{2}$ pipelines. Knowledge is available in all three countries on onshore pipelines. Both the study of analogue pipeline trajectories (see Section 3.2 and Appendix B) and local experts (workshop 3; interviews $1,2,3$ ) indicated that Spanish stakeholders have detailed technical knowledge on the design, construction and operation of offshore pipelines.

- There is long worldwide experience with high pressure $\mathrm{CO}_{2}$ pipeline transport - especially naturally occurring $\mathrm{CO}_{2}$ from underground sources in North America - designated for enhanced oil recovery (EOR) (Element Energy Limited, 2010a; Insight Economics, 2011; SSEB, 2010).

\subsubsection{Barriers}

- Few engineers and professionals worldwide have the experience and skills to make appropriate designs for the transport of captured $\mathrm{CO}_{2}$ (Element Energy Limited, 2010a), especially with respect to offshore transport over long distances. For that reason, demonstration projects are desirable to accumulate experience.

- The potential intermittency character of captured $\mathrm{CO}_{2}$ flows poses challenges for pipeline transport operators. Significant fluctuations in $\mathrm{CO}_{2}$ flows can lead to depressurization, temperature drop and phase changes, which can have an impact on the pipe's structural integrity, lead to solid $\mathrm{CO}_{2}$ deposits forming plugs and metallurgical damage (embrittlement and fracture; damage to lining or coatings; ice coating in subsea pipelines) (Ramírez et al., 2011). Temperature and pressure buffers can only partly neutralize these effects. The operating philosophy including start-up and shut-down procedures developed for a point-to-point $\mathrm{CO}_{2}$ pipeline designed for the ROAD CCS demonstration project in the Netherlands could be an example how to deal with the intermittency character (Road CCS, 2013). Additionally, more knowledge is needed on the thermodynamic behavior of $\mathrm{CO}_{2}$ pipeline flows by doing (laboratory) research and developing sophisticated modeling tools (Element Energy Limited, 2010a). Although alleviation measures (e.g. matching supply and demand of $\mathrm{CO}_{2}$; supply/off-take agreements; $\mathrm{CO}_{2}$ storage tanks; start-up, shut-down, emergency and blowdown procedures; contingency planning, or storage of gaseous $\mathrm{CO}_{2}$ in the pipeline ${ }^{3}$ ) are available, these may increase the cost of $\mathrm{CO}_{2}$ pipeline transport.

- Insufficient knowledge is available on the physicochemical properties of $\mathrm{CO}_{2}$ flows containing impurities. Impurities can affect the pipeline transportation capacity, the $\mathrm{CO}_{2}$ phase diagram, and the physical properties (e.g. viscosity, heat capacity, compressibility). Hence, certain $\mathrm{CO}_{2}$ flows require a pipeline design that can withstand pipeline fracturing, hydrate formation, corrosion and two-phase flows (Ramírez et al., 2011). Although the basic $\mathrm{CO}_{2}$ transport principles are understood, the interplay among the various impurities, their effect on the physicochemical properties of $\mathrm{CO}_{2}$ and pipeline integrity is not completely clear yet. Furthermore, while technical measures are available to solve most of these problems (e.g. high grade steel, coatings), these may increase the costs of $\mathrm{CO}_{2}$ transport considerably. Lessons need to be drawn from $R \& D$ programs set up to increase the knowledge base and bring down the costs of anthropogenic, dense phase $\mathrm{CO}_{2}$ pipeline transport (such as COOLTRANS, $\mathrm{CO}_{2}$ PipeHaz, $\mathrm{SARCO}_{2}$, PIPETRANS).

- There is a knowledge gap on the probability of a $\mathrm{CO}_{2}$ pipeline failure and the (fatal) impact it could have on human beings (Koornneef et al., 2010; Ramírez et al., 2011). In the United States, 10 significant and 18 non-significant incidents ${ }^{4}$ with pipelines transporting naturally occurring $\mathrm{CO}_{2}$ were observed in the period 1986 to mid-2003 (PHMSA, 2013), resulting in an estimated failure frequency of $6.3 \times 10^{-5} \mathrm{yr}^{-1} \mathrm{~km}^{-1}$ and $1.75 \times 10^{-4} \mathrm{yr}^{-1} \mathrm{~km}^{-1}$ for only significant and for both significant and non-significant incidents, respectively (Knoope et al., 2014b). However, the installed capacity is too low to derive reliable figures. Knoope et al. (2014b) argued that failure frequencies based on natural gas pipelines $\left(1.62 \times 10^{-4} \mathrm{yr}^{-1} \mathrm{~km}^{-1}\right.$ in the EU over the period 2006-2010; $1.05 \times 10^{-4} \mathrm{yr}^{-1} \mathrm{~km}^{-1}$ in the U.S. over the period 1993-2012), which are often used in literature as a proxy for $\mathrm{CO}_{2}$ pipelines, provide conservative (i.e. pessimistic) estimations. This is due to the fact that $\mathrm{CO}_{2}$ pipelines will likely operate under more favorable conditions, like a larger wall thickness that makes them more resistant to external interference and corrosion. A study by the Health and Safety Laboratory (2009) suggest that $\mathrm{CO}_{2}$ pipelines are safer, or at least as safe as natural gas pipelines. Knoope et al. (2014b) concluded that the risks of liquid $\mathrm{CO}_{2}$ pipeline transport are most likely manageable and widely accepted under current legislative frameworks, even without risk mitigation measures (e.g. increasing soil coverage, concrete slabs, market tape). In addition, risk mitigation measures can be applied in densely populated areas, which will increase specific pipeline costs with around $4 \%$. Gaseous $\mathrm{CO}_{2}$ transport shows higher risks, especially for large mass flows, and requires considerable safety zones (100-770 meters depending on the mass flow and applied risk mitigation measures) to meet Dutch safety regulations (Knoope et al., 2014b). Several R\&D programs include experiments with $\mathrm{CO}_{2}$ pipelines to validate dispersion models and toxicity of $\mathrm{CO}_{2}$ in order to provide a better understanding of the effects of a pipeline failure. More insight is needed on the

\footnotetext{
${ }^{3}$ An example of a $\mathrm{CO}_{2}$ pipeline using pressure swings to accommodate mismatches in supply and demand is the OCAP pipeline in the Netherlands. At night, $\mathrm{CO}_{2}$ is stored in the pipeline, resulting in a pressure swing during the day from 20 bars in the morning to 10 bars by the end of the day (RCI, 2009). This example shows that there is scope for 'pipeline storage' in the gaseous phase; yet, confirmation for storage potential at higher pressures is required and merits further research.

4 PHMSA (2013) refers to significant incidents when any of the following consequences occur: "(i) fatality or injury requiring in-patient hospitalization; (ii) $\$ 50,000$ or more in total costs, measured in 1984 dollars; (iii) highly volatile liquid releases of 5 barrels or more or other liquid releases of 50 barrels or more; (iv) liquid releases resulting in an unintentional fire or explosion." The total costs of 50,000 $\$ 1984$ translate to around $80,000 € 2010$. The physical conditions (temperature, pressure) of a barrel were not indicated.
} 
Table 4

Overview and comparison of drivers, synergies and barriers related to technology. ${ }^{\text {a }}$

\begin{tabular}{|c|c|c|c|c|c|}
\hline & Type of results & International literature & Spain & Portugal & Morocco \\
\hline \multicolumn{6}{|l|}{ DRIVERS } \\
\hline $\begin{array}{l}\text { Long experience with designing, constructing and } \\
\text { operating pipeline networks carrying natural gas and oil, } \\
\text { both on- and offshore }\end{array}$ & GPT & $\sqrt{ }$ & $\sqrt{ }$ & $\sqrt{ }^{b}$ & + \\
\hline $\begin{array}{l}\text { Experience with transport of } \mathrm{CO}_{2} \text { (for EOR, chemical } \\
\text { industry and food industry) }\end{array}$ & GPT & $\sqrt{ }$ & $\sqrt{ }$ & $\sqrt{ }$ & + \\
\hline \multicolumn{6}{|l|}{ BARRIERS } \\
\hline $\begin{array}{l}\text { Few engineers/professionals available that can make } \\
\text { sound designs for safe transport of anthropogenic } \mathrm{CO}_{2}\end{array}$ & GPT & $\sqrt{ }$ & + & + & $\sqrt{ }$ \\
\hline $\begin{array}{l}\text { Knowledge gap on effect of intermittent flow character on } \\
\text { the thermodynamic behaviour of } \mathrm{CO}_{2}\end{array}$ & GPT & $\sqrt{ }$ & $\sqrt{ }$ & $\sqrt{ }$ & $\sqrt{ }$ \\
\hline $\begin{array}{l}\text { Knowledge gap on effect of impurities on the } \\
\text { physicochemical behaviour of } \mathrm{CO}_{2} \text { and pipeline design }\end{array}$ & GPT & $\sqrt{ }$ & $\sqrt{ }$ & $\sqrt{ }$ & $\sqrt{ }$ \\
\hline $\begin{array}{l}\text { Knowledge gap on the probabilities and impacts of a } \\
\text { pipeline failure. }\end{array}$ & GPT & $\sqrt{ }$ & + & $\sqrt{ }$ & + \\
\hline $\begin{array}{l}\text { Experience with (high-pressure) } \mathrm{CO}_{2} \text { pipeline transport in } \\
\text { Spain, Portugal and Morocco is virtually non-existent. }\end{array}$ & GPT & Not identified & $\sqrt{ }$ & $\sqrt{ }$ & $\sqrt{ }$ \\
\hline $\begin{array}{l}\text { Lack of } \mathrm{CO}_{2} \text { specific tools such as hydraulic } \mathrm{CO}_{2} \text { simulators } \\
\text { and commercial systems to control leakage. }\end{array}$ & GPT & $\sqrt{ }$ & $\sqrt{ }$ & + & + \\
\hline $\begin{array}{l}\text { Large altitude differences make the installation and } \\
\text { maintenance of pipelines more difficult. Also insufficient } \\
\text { knowledge is available on the effect of altitude on the } \\
\text { properties of } \mathrm{CO}_{2} \text {. }\end{array}$ & SPT & Not identified & $\sqrt{ }$ & + & + \\
\hline $\begin{array}{l}\text { Laying } \mathrm{CO}_{2} \text { pipelines in designated corridors in parallel to } \\
\text { existing pipelines could be difficult or even technically } \\
\text { impossible, because of spatial limitations }\end{array}$ & SPT & Not identified & $\sqrt{ }$ & $\sqrt{ }$ & + \\
\hline
\end{tabular}

a The DBS are categorized in different types of results, namely: applying to CCS in general (GCCS), $\mathrm{CO}_{2}$ pipeline transport in general (GPT), and specific CO 2 pipeline transport

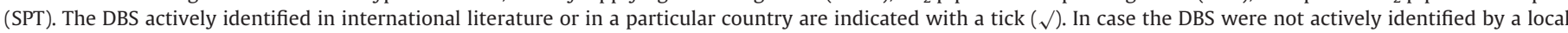

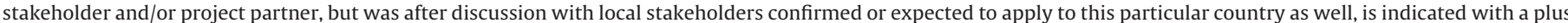

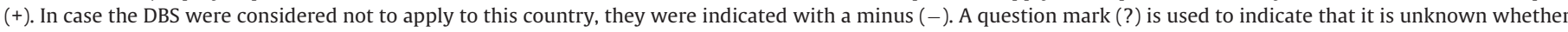

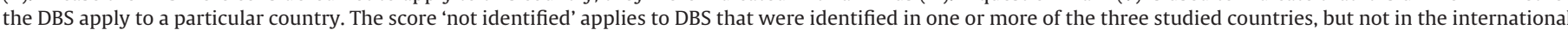

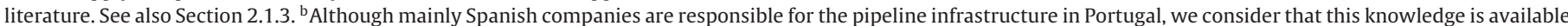
in Portugal.

probability and effects of a $\mathrm{CO}_{2}$ pipeline failure in order to take adequate and cost effective risk mitigation measures.

- Local stakeholders in Spain, Portugal and Morocco report that experience with $\mathrm{CO}_{2}$ pipeline transport is virtually non-existent (workshops 1,2,3; interviews 1,2,3). CCS demonstration projects and knowledge transfer from abroad are therefore needed.

- $\mathrm{CO}_{2}$ specific tools for modeling and leakage control to warrant safe and sound $\mathrm{CO}_{2}$ pipeline transport are not yet developed. It is essential at that static and dynamic hydraulic simulators of variable composition $\mathrm{CO}_{2}$ streams will make better projections of $\mathrm{CO}_{2}$ flow behavior (interview 3 ).

- Geographical altitude differences are a determinant factor in the planning of a pipeline network (workshop 2, 3; interviews 1, 2). Mountainous terrains should be avoided to the extent possible so as to reduce technical difficulties and costs for design, construction and operation. Furthermore, the effect of altitude differences on the properties of $\mathrm{CO}_{2}$ is rather unknown and requires further research (interviews $1,2,3$ ).

- Laying $\mathrm{CO}_{2}$ pipelines in designated corridors in parallel to existing pipelines could be difficult or even technically impossible, because of spatial limitations (workshop 2,3). To avoid delay during the construction phase, timely action is required by reserving space in pipeline corridors or land for alternative pipeline tracks.

\subsection{Legislation and policy}

The main findings of the legislative DBS are presented in Table 5.

\subsubsection{Drivers and synergies}

- The extensive legislative body on hydrocarbon pipeline transport constitutes a good basis for $\mathrm{CO}_{2}$ pipeline transport. Both literature (e.g. Element Energy Limited, 2010a; SSEB, 2010) and local stakeholders (interviews 1,2,3) indicated that, if needed, existing legislation on hydrocarbon pipeline transport can be applied to fill in most of the regulatory gaps for $\mathrm{CO}_{2}$ pipeline transport.

- The adoption of the EU CCS Directive 2009/31/EC governing inter alia third party access to pipeline networks, monitoring and reporting guidelines on $\mathrm{CO}_{2}$ emissions and transboundary $\mathrm{CO}_{2}$ transport, has been a major step in laying the legal foundation for $\mathrm{CO}_{2}$ transport. This directive has been transposed to both Portuguese and Spanish law in the respective years 2012 and 2011 (Shogenova et al., 2013).

- Earmarking pipeline ventures as public interest projects can expedite legal procedures (interviews 1, 2, 3).

- In some cases, Right of Way (ROW) - i.e. an easement to use a strip of land for a particular purpose - of existing pipelines can be utilized for future $\mathrm{CO}_{2}$ pipelines, which could avoid delay caused by legal procedures for acquiring new ROW (interviews 1,2,3). However, this is only possible if sufficient space is available for multiple pipelines (see Section 4.1).

\subsubsection{Barriers}

- There is a lack of clarity on (the interactions between) EU and national policy objectives related to $\mathrm{CO}_{2}$ emission reductions, energy efficiency improvements and renewable energy targets, which causes confusion and uncertainty among stakeholders (workshop 3). In addition, uncertainty on policy on economic incentives (e.g. EU Emission Trading Scheme, $\mathrm{CO}_{2}$ emission caps, taxes, public investments in $\mathrm{CO}_{2}$ pipeline projects) for $\mathrm{CCS}$ in general and $\mathrm{CO}_{2}$ pipeline transport in particular constitutes a major barrier (workshops 2,3; interviews 1,2,3). Governments publishing policy commitments or offering long term financial 
Table 5

Overview and comparison of drivers, synergies and barriers related to legislation and policy. ${ }^{\mathrm{a}}$

\begin{tabular}{|c|c|c|c|c|c|}
\hline & Type of results & International literature & Spain & Portugal & Morocco \\
\hline \multicolumn{6}{|l|}{ DRIVERS/SYNERGIES } \\
\hline $\begin{array}{l}\text { Use of existing legislation to fill existing gaps for codes and } \\
\text { guidelines for transporting } \mathrm{CO}_{2}\end{array}$ & GPT & $\sqrt{ }$ & $\sqrt{ }$ & $\sqrt{ }$ & + \\
\hline Adoption of EU CCS Directive 2009/31/EC & GPT & $\sqrt{ }$ & $\sqrt{ }$ & $\sqrt{ }$ & - \\
\hline $\begin{array}{l}\text { Earmarking } \mathrm{CO}_{2} \text { pipeline ventures as public interest } \\
\text { projects can expedite legal procedures, and thus, the } \\
\text { implementation of } \mathrm{CO}_{2} \text { pipeline projects }\end{array}$ & GPT & Not identified & $\sqrt{ }$ & $\sqrt{ }$ & + \\
\hline $\begin{array}{l}\text { If possible, the use of existing ROW facilitates the process } \\
\text { of building new pipelines }\end{array}$ & GPT & Not identified & $\sqrt{ }$ & $\sqrt{ }^{b}$ & + \\
\hline \multicolumn{6}{|l|}{ BARRIERS } \\
\hline $\begin{array}{l}\text { Lack of clarity and uncertainty on policy objectives on } \mathrm{CO}_{2} \\
\text { emission reductions, renewables, and energy efficiency } \\
\text { as well as on economic incentives for CCS in general and } \\
\mathrm{CO}_{2} \text { pipeline transport in particular }\end{array}$ & GCCS/GPT & $\sqrt{ }$ & $\sqrt{ }$ & $\sqrt{ }$ & $\sqrt{ }$ \\
\hline $\begin{array}{l}\text { Several aspects of pipeline transport of anthropogenic } \\
\mathrm{CO}_{2} \text { designated for storage are not (sufficiently) covered } \\
\text { in national law and regulations }\end{array}$ & GPT & $\sqrt{ }$ & $\sqrt{ }$ & $\sqrt{ }$ & $\sqrt{ }$ \\
\hline $\begin{array}{l}\text { Transboundary } \mathrm{CO}_{2} \text { transport is currently not possible } \\
\text { under London Protocol due to slow ratification process } \\
\text { of the amendment of Article } 6\end{array}$ & GPT & $\sqrt{ }$ & + & + & + \\
\hline $\begin{array}{l}\text { No explicit definition of captured anthropogenic } \mathrm{CO}_{2} \text { in the } \\
\text { Basel Convention }\end{array}$ & GPT & $\sqrt{ }$ & + & + & + \\
\hline $\begin{array}{l}\text { National future legislation on } \mathrm{CO}_{2} \text { transport can differ per } \\
\text { country, thereby complicating transboundary transport }\end{array}$ & GPT & $\sqrt{ }$ & $\sqrt{ }$ & + & + \\
\hline $\begin{array}{l}\text { Liability for harm caused by accidents or leaks from } \mathrm{CO}_{2} \\
\text { pipelines or other transport facilities is unclear and } \\
\text { creates uncertainty among potential pipeline owners } \\
\text { and operators }\end{array}$ & GPT & $\sqrt{ }$ & + & $\sqrt{ }$ & + \\
\hline $\begin{array}{l}\text { Procedures to acquire ROW can be difficult and hamper a } \\
\text { rapid build out of pipeline networks }\end{array}$ & GPT & $\sqrt{ }$ & $\sqrt{ }$ & $\sqrt{ }$ & $\sqrt{ }$ \\
\hline $\begin{array}{l}\text { Land use planning regulations obliging pipeline developers } \\
\text { to avoid designated areas can result in additional costs } \\
\text { and a delay in } \mathrm{CO}_{2} \text { pipeline deployment }\end{array}$ & GPT & $\sqrt{ }$ & $\sqrt{ }$ & $\sqrt{ }$ & $\sqrt{ }$ \\
\hline $\begin{array}{l}\text { Lengthy permit procedures can delay a rapid build out of } \\
\text { pipeline networks, especially if multiple countries with } \\
\text { different permit procedures are involved }\end{array}$ & GPT & $\sqrt{ }$ & + & $\sqrt{ }$ & $?$ \\
\hline $\begin{array}{l}\text { Establishing jurisdiction and responsibilities among } \\
\text { national and local government actors is often difficult }\end{array}$ & GPT & Not identified & + & $\sqrt{ }$ & $?$ \\
\hline
\end{tabular}

a The DBS are categorized in different types of results, namely: applying to CCS in general (GCCS), $\mathrm{CO}_{2}$ pipeline transport in general (GPT), and specific CO 2 pipeline transport

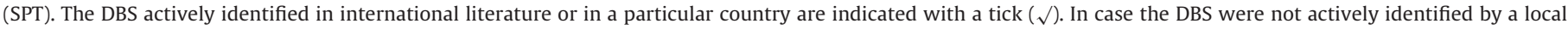

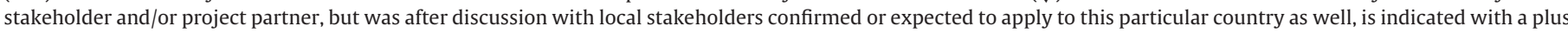

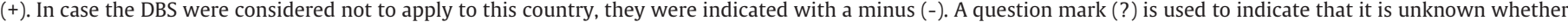

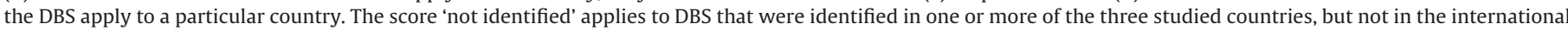
literature. See also Section 2.1.3.

commitments would alleviate this uncertainty (Mikunda et al., 2011b).

- Several aspects of pipeline transport of anthropogenic $\mathrm{CO}_{2}$ designated for storage are not (sufficiently) covered in national law and regulations. Det Norske Veritas (2010) published a recommended practice and set out basic specific codes for $\mathrm{CO}_{2}$ pipeline design, construction and operation, which serves as a supplement to existing pipeline standards. Notwithstanding, several national regulations and acts have to be amended or clarified to encompass transport of anthropogenic $\mathrm{CO}_{2}$. Furthermore, additional guidelines may have to be designed to fill in remaining regulatory gaps. Examples of issues not (sufficiently) addressed in national jurisdictions are health, safety and environmental aspects, standards for $\mathrm{CO}_{2}$ stream conditions (e.g. acceptable impurity levels), siting of $\mathrm{CO}_{2}$ pipelines, and procedures on tariff setting of pipeline capacity (Element Energy Limited, 2010a; European Union, 2012; Mikunda et al., 2011a; UCL, 2014) (interviews 1,2,3). More research is needed to identify the specific regulatory needs for Spain, Portugal and Morocco.

- Article 6 of the London Protocol prohibits contracting parties (incl. Spain, Portugal and Morocco) from allowing the export of wastes to other countries or dumping at sea. Article 6 was amended by contracting parties to allow transboundary $\mathrm{CO}_{2}$ transport designated for sub-seabed storage, but requires ratification of two-third of the contracting parties ( 28 out of 42 ) to enter into force (Mikunda et al., 2011b; Warren, 2012). To date, only the UK and Norway have ratified the amendment, and it is unlikely that two-third of the parties will have ratified the amendment in the near term for a number of reasons, amongst others because CCS has a low priority for several contracting parties (Garrett and McCoy, 2013). Several legal solutions were proposed by an IEA working paper (IEA, 2011) to facilitate transboundary $\mathrm{CO}_{2}$ transport based on the international rules of treaty interpretation. Garrett and McCoy (2013) considered that a provisional application of the Article 6 amendment would be the fastest and most straightforward solution. No studies or documents were found making statements on the expected period needed to solve this issue. As long as the London Protocol has not been ratified, transboundary $\mathrm{CO}_{2}$ transport for the purpose of sub-seabed storage is prohibited.

- The Basel Convention (on the Control of Transboundary Movements of Hazardous Wastes and Their Disposal) lacks a clear definition of captured $\mathrm{CO}_{2}$ (Macrory et al., 2013). Uncertainty exists whether $\mathrm{CO}_{2}$ should be classified as a hazardous substance or not. If $\mathrm{CO}_{2}$ is classified as a hazardous waste, several barriers will arise on regard to transboundary $\mathrm{CO}_{2}$ transport across states (Element Energy Limited, 2010a; Raine, 2008). For example, $\mathrm{CO}_{2}$ 
export may only be allowed for countries that do not have storage capacity themselves, or cost increases and delays may occur due to the requirement to submit documents and notifications. Explicit definitions of $\mathrm{CO}_{2}$ flows in terms of physicochemical properties (e.g. impurities, phase) during transport are needed to eliminate this uncertainty, and clarify the status of $\mathrm{CO}_{2}$, either as a pollutant, commodity, or both. To the knowledge of Macrory et al. (2013), new definitions of $\mathrm{CO}_{2}$ have not been made by any of the convention parties (incl. Spain, Portugal and Morocco). No studies or documents were found making statements on the expected period needed to solve this issue.

- Inconsistency in countries' jurisdictions on technical standards on $\mathrm{CO}_{2}$ pipeline design, construction and operation (e.g. design and operating pressure, max. allowable impurity levels) as well as conditions on third party access to pipeline facilities could complicate transboundary $\mathrm{CO}_{2}$ transport, both inside and outside the EU (Insight Economics, 2011). Moreover, state laws may conflict over pipeline control and management. Concerted action of governments is needed to solve cross-jurisdictional issues and align regulations to the extent possible. Another solution is the use of multi-lateral agreements between states and companies; today, such agreements are often used in transboundary pipeline projects to solve similar issues (Insight Economics, 2011; Mikunda et al., 2011a; World Bank, 2011).

- Liability for harm caused by accidents or leaks from $\mathrm{CO}_{2}$ pipelines or other transport facilities is unclear and creates uncertainty among potential pipeline owners and operators (UCL, 2014) (interview 2). This topic should be addressed clearly in legislation.

- Procedures to acquire ROW can be difficult and hamper a rapid build out of pipeline networks. Acquiring ROW from too many land owners can be a major problem (interviews 1, 2; workshop 1). In Morocco, this is also due to the different types of property rights (incl. ancestral land), which makes the transfer of land from the original owners difficult. Financial incentives can help to alleviate this problem (workshop 1).

- Land use planning regulations pertaining to special areas - such as protected nature reserves, military zones and sites of historical or special interest - oblige pipeline developers to make detours, which can result in additional costs and a delay of the project (Element Energy Limited, 2010a). Examples of such regulations in Portugal are the Municipality Plans (e.g. notification $\mathrm{N}^{\circ} 6562 / 2010$; notification no 11622/2012) (Municipality Coimbra, 2010; Municipality Lisbon, 2012), National Agricultural Reserve (Decree-Law no 73/2009) (MARDF, 2009) and National Ecological Reserve (Decree-Law 239/2012) (MASESP, 2012). Using planning and modelling tools in an early stage can help to identify cost effective solutions and avoid delay of the project.

- Lengthy permit procedures impede a fast implementation of $\mathrm{CO}_{2}$ transport pipelines. Permit procedures can differ per country and land zone (residential vs. rural area) due to varying lead times, environmental regulations and possibility for third persons to appeal to a higher administrative court requesting a formal change to the official decision made. In case several countries are involved, project managers have to await the outcome of the slowest permit procedure (European Union, 2012). In Portugal, several provincial regions and municipalities crossed by a potential pipeline route have to give positive feedback on the project proposal, which is a very time consuming process (interview 2). Applying for permits in an early stage and labelling pipeline ventures as public interest projects can avoid delay of the project.

- Establishing jurisdiction and responsibilities on $\mathrm{CO}_{2}$ pipelines among public administrations (e.g. national and local government actors) can be difficult. Close communication among different government levels is therefore important (interview 3 ).

\subsection{Economics and finance}

The main findings of the economic and financial DBS are presented in Table 6.

\subsubsection{Drivers and synergies}

- The main economic driver relates to a national or international financial-regulatory framework (e.g. emission trading scheme (ETS), carbon tax, favourable loans, tax incentives) to create a market for CCS (Element Energy Limited, 2010a; European Union, 2012; Insight Economics, 2011).

- Economic revenues can be created by utilizing captured $\mathrm{CO}_{2}$ for EOR, greenhouses, food and chemical industry and biofuel production (Chrysostomidis and Zakkour, 2008; Insight Economics, 2011). Although several experts expected the potential for $\mathrm{CO}_{2}$ utilization in the WMR to be limited (workshops 2 and 3) research is needed to determine whether such opportunities exist or not, especially for greenhouses in the Spanish horticulture sector.

- Future $\mathrm{CO}_{2}$ pipeline projects can benefit from the large experience accumulated by energy firms and project developers with investments models for natural gas and oil pipeline networks (SSEB, 2010) (interviews 2, 3). An extensive overview of available investment models available for $\mathrm{CO}_{2}$ pipelines can be found in Chrysostomidis and Zakkour (2008).

- Economic synergies can be achieved by oversizing $\mathrm{CO}_{2}$ trunk pipelines or amalgamating demand for pipeline capacity to exploit economies of scale (Chrysostomidis and Zakkour, 2008; Mikunda et al., 2011b). Knoope et al. (2014a) showed that oversizing of $\mathrm{CO}_{2}$ trunk pipelines is economically interesting in case the oversized capacity is used not later than five to ten years after the construction of the pipeline ${ }^{5}$.

- The re-use of existing pipelines for $\mathrm{CO}_{2}$ transport can save significant investment cost ${ }^{6}$ (Insight Economics, 2011). However, the potential for re-use of existing pipelines is expected to be minor in the WMR (workshops 2,3; interviews 1,2,3).

- In case $\mathrm{CO}_{2}$ pipelines can be installed parallel to other pipelines, bundling monitoring and maintenance activities can reduce costs significantly (interviews 1,3).

\subsubsection{Barriers}

- In total, eight economic/financial barriers were identified, of which four in international literature.

- The current low $\mathrm{CO}_{2}$ price and the uncertainty on future $\mathrm{CO}_{2}$ prices and government's commitments to $\mathrm{EU} \mathrm{CO}_{2}$ emission allowances render it impossible to make a robust business case for CCS (Chrysostomidis and Zakkour, 2008; Sanders et al., 2013) (interviews 1,2,3). A possible solution is to reform the ETS by reducing the number of emission allowances in order to increase the $\mathrm{CO}_{2}$ price and create a market for CCS (ZEP, 2013).

- The high level and high risk profile of investments in a $\mathrm{CO}_{2}$ pipeline (network) is considered to be one of the main economic barriers (Chrysostomidis and Zakkour, 2008; Sanders et al., 2013) (interviews 1,2,3). The uncertainties on the technological feasibility, economic revenues, policy, legislation, market development and public acceptance is deemed unacceptable by investors (Sanders et al., 2013). The government could reduce uncertainty by settling outstanding legal issues and make clear (legally binding) commitments on CCS for the future. Furthermore, the

\footnotetext{
5 This statement holds for two equal sized point sources in close proximity to each other $(10 \mathrm{~km})$ and using a real discount rate of $10 \%$.

6 The possibilities for re-use depend on many factors, such as the design pressure of the existing pipeline, capacity, impurities in the $\mathrm{CO}_{2}$ stream, pipeline materials remaining service life and availability of the pipeline.
} 
Table 6

Overview and comparison of drivers, synergies and barriers related to economics and finance. ${ }^{\text {a }}$

\begin{tabular}{|c|c|c|c|c|c|}
\hline & Type of results & International literature & Spain & Portugal & Morocco \\
\hline \multicolumn{6}{|l|}{ DRIVERS/SYNERGIES } \\
\hline $\begin{array}{l}\text { Financial-regulatory framework including for example: } \\
\text { ETS, carbon tax, beneficial discount rates, tax incentives, } \\
\text { subsidies at local, regional, national and international } \\
\text { level }\end{array}$ & GCCS & $\sqrt{ }$ & + & $\sqrt{ }$ & + \\
\hline $\begin{array}{l}\text { The use of } \mathrm{CO}_{2} \text { for the production of synthetic methane, } \\
\text { enhanced hydrocarbon recovery, greenhouses, food and } \\
\text { chemical industry and biofuel production can drive the } \\
\text { market for CCS }\end{array}$ & GCCS & $\sqrt{ }$ & + & $\sqrt{ }$ & + \\
\hline $\begin{array}{l}\text { Large experience of energy companies and project } \\
\text { developers with investments models for the } \\
\text { development of natural gas and oil pipeline networks }\end{array}$ & GPT & $\sqrt{ }$ & $\sqrt{ }$ & $\sqrt{ }$ & + \\
\hline $\begin{array}{l}\text { Oversizing pipelines or amalgamating demand for pipeline } \\
\text { capacity to exploit economies of scale }\end{array}$ & SPT & $\sqrt{ }$ & + & $\sqrt{ }$ & + \\
\hline $\begin{array}{l}\text { Bundling monitoring and maintenance activities when } \mathrm{CO}_{2} \\
\text { pipelines can be installed parallel to other pipelines can } \\
\text { reduce costs }\end{array}$ & SPT & Not identified & $\sqrt{ }$ & $\sqrt{ }$ & + \\
\hline $\begin{array}{l}\text { Re-use of existing pipelines to reduce costs for materials } \\
\text { and construction }\end{array}$ & SPT & $\sqrt{ }$ & + & + & + \\
\hline \multicolumn{6}{|l|}{ BARRIERS } \\
\hline $\begin{array}{l}\text { The low price of } \mathrm{CO}_{2} \text { makes it virtually impossible to make } \\
\text { a robust business case for CCS }\end{array}$ & GCCS & $\sqrt{ }$ & $\sqrt{ }$ & $\sqrt{ }$ & + \\
\hline $\begin{array}{l}\text { High level and risk profile of investments in } \mathrm{CO}_{2} \text { transport } \\
\text { infrastructure is often considered to be unacceptable by } \\
\text { private investors }\end{array}$ & GPT & $\sqrt{ }$ & $\sqrt{ }$ & $\sqrt{ }$ & + \\
\hline $\begin{array}{l}\text { Uncertainty on future } \mathrm{CO}_{2} \text { pipeline demand is a barrier to } \\
\text { private firms oversizing } \mathrm{CO}_{2} \text { transport pipelines }\end{array}$ & GPT & $\sqrt{ }$ & + & + & + \\
\hline $\begin{array}{l}\text { The economic crisis delays CCS demonstration projects, } \\
\text { which are needed to reduce the (perceived) risk for } \\
\text { investors }\end{array}$ & GPT & Not identified & $\sqrt{ }$ & + & + \\
\hline $\begin{array}{l}\text { Geographical altitude differences can increase the costs of } \\
\mathrm{CO}_{2} \text { transport significantly }\end{array}$ & SPT & Not identified & $\sqrt{ }$ & $\sqrt{ }$ & + \\
\hline $\begin{array}{l}\text { Need for an electric infrastructure for the booster stations } \\
\text { to repressurize the } \mathrm{CO}_{2}\end{array}$ & GPT & Not identified & $\sqrt{ }$ & $\sqrt{ }$ & + \\
\hline $\begin{array}{l}\text { Private investors may delay or even refrain from investing } \\
\text { in } \mathrm{CO}_{2} \text { pipelines due to the risk of high and variable steel } \\
\text { prices }\end{array}$ & GPT & $\sqrt{ }$ & $\sqrt{ }$ & + & + \\
\hline $\begin{array}{l}\text { Taxes levied in different Moroccan administrative areas } \\
\text { could increase the costs of transport significantly }\end{array}$ & GPT & Not identified & - & - & $\sqrt{ }$ \\
\hline
\end{tabular}

a The DBS are categorized in different types of results, namely: applying to CCS in general (GCCS), $\mathrm{CO}_{2}$ pipeline transport in general (GPT), and specific CO 2 pipeline transport

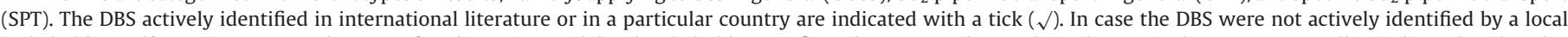

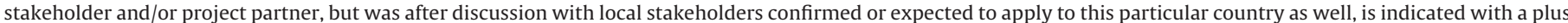

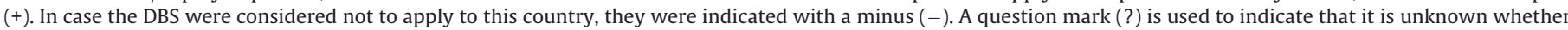

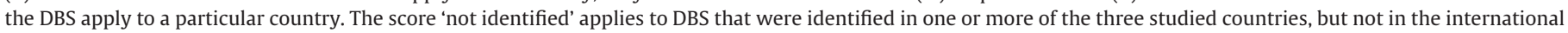
literature. See also Section 2.1.3.

establishment of a strong, well-functioning financial-regulatory framework and the provision of financial guarantees to private investors are needed to safeguard their investments (Element Energy Limited, 2010a).

- Private investors may refrain from oversizing $\mathrm{CO}_{2}$ pipelines due to the risk of low demand for $\mathrm{CO}_{2}$ pipeline capacity in the future. This could result in higher total investment cost for pipeline capacity from a societal point of view as economies of scale will not be fully exploited (Chrysostomidis and Zakkour, 2008; Mikunda et al., 2011b). Governments could alleviate this problem by promoting investors to amalgamate their demand for pipeline capacity by, for example, obliging project developers to hold open seasons ${ }^{7}$, and making explicit agreements on future usage of the pipeline. Other possible options are public or public-private finance constructions and financial rewards for shareholders and/or private investors who are exposed to the risk of future pipeline demand (Chrysostomidis and Zakkour, 2008; Mikunda et al., 2011b). Striking the right balance between risk, revenues

\footnotetext{
7 In an open season, a pipeline project developer makes it possible for other parties in the market to join the project. Open seasons act as an insurance that pipeline project developers provide an efficient level of capacity and exploit economies of scale.
}

and the sources of finance is quintessential in creating a commercially viable $\mathrm{CO}_{2}$ network (Chrysostomidis and Zakkour, 2008; Mikunda et al., 2011b).

- The economic crisis has had a delaying effect on the deployment of CCS demonstration projects, which are needed to demonstrate the technological feasibility of the entire CCS chain (including $\mathrm{CO}_{2}$ pipeline transport) (interviews 1,2,3).

- Large geographical altitude differences in the WMR are a countryspecific barrier (interview 3; workshops 2,3). Running pipelines across mountainous areas could significantly increase the cost of $\mathrm{CO}_{2}$ pipeline transport due to large pressure drops, and should therefore be avoided to the extent possible. Higher operating pipeline pressures were suggested for Spain so as to avoid the need for booster stations along pipeline routes (interview 3).

- Natural gas pipelines can deliver their own energy to booster stations along pipeline routes, which are needed to repressurize the transported gas. However, $\mathrm{CO}_{2}$ pipelines would require an electric infrastructure to power the booster stations. Installing such an infrastructure would increase the cost of a $\mathrm{CO}_{2}$ pipeline network considerably, especially in remote areas without direct access to electric power sources (interviews 1,2,3).

- Private investors may delay or even refrain from investing in $\mathrm{CO}_{2}$ pipelines due to the risk of high and variable steel prices, 
Table 7

Overview and comparison of drivers, synergies and barriers related to organization. ${ }^{\mathrm{a}}$

\begin{tabular}{|c|c|c|c|c|c|}
\hline & Type of results & International literature & Spain & Portugal & Morocco \\
\hline \multicolumn{6}{|l|}{ DRIVERS/SYNERGIES } \\
\hline $\begin{array}{l}\text { Experience with organizational models of natural gas } \\
\text { pipeline projects crossing international borders, which } \\
\text { provides valuable lessons on issues such as permitting, } \\
\text { construction and operation of the pipeline infrastructure } \\
\text { spanning national borders }\end{array}$ & GPT & $\sqrt{ }$ & $\sqrt{ }$ & $\sqrt{ }$ & + \\
\hline \multicolumn{6}{|l|}{ BARRIERS } \\
\hline $\begin{array}{l}\text { Differences in countries' organizational models of } \\
\text { transport networks may constitute a barrier for future } \\
\text { transboundary } \mathrm{CO}_{2} \text { transport networks }\end{array}$ & GPT & $\sqrt{ }$ & $\sqrt{ }$ & $\sqrt{ }$ & + \\
\hline $\begin{array}{l}\text { Insufficient planning and communication among } \\
\text { stakeholders and countries could result in a sub-optimal } \\
\text { buildout, delay and increased costs of a } \mathrm{CO}_{2} \text { pipeline } \\
\text { network }\end{array}$ & GPT & $\sqrt{ }$ & + & + & + \\
\hline $\begin{array}{l}\text { Insufficient scheduling between the pipeline network and } \\
\mathrm{CO}_{2} \text { capture in industries and power plants could } \\
\text { become a barrier. Scheduling among the different parts } \\
\text { of the CCS infrastructure is essential }\end{array}$ & GPT & $\sqrt{ }$ & + & $\sqrt{ }$ & + \\
\hline $\begin{array}{l}\text { The complicated relationships between regions within a } \\
\text { country could make } \mathrm{CO}_{2} \text { pipeline transport from one } \\
\text { region to the other problematic }\end{array}$ & GPT & Not identified & $\sqrt{ }$ & - & $?$ \\
\hline
\end{tabular}

a The DBS are categorized in different types of results, namely: applying to CCS in general (GCCS), $\mathrm{CO}_{2}$ pipeline transport in general (GPT), and specific $\mathrm{CO}_{2}$ pipeline transport

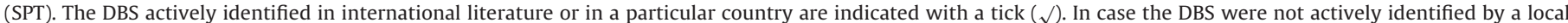

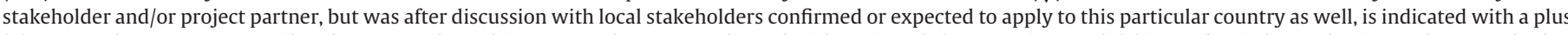

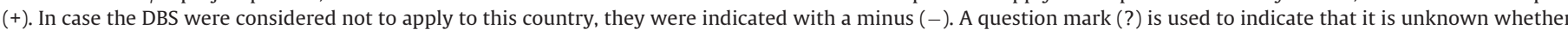

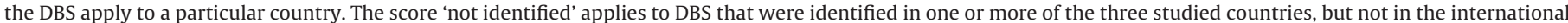
literature. See also Section 2.1.3.

which have a large impact on the total pipeline cost (interview 3 ). Long term contracts can reduce uncertainties of steel price fluctuations.

- The taxes levied in Moroccan administrative areas could increase the costs of $\mathrm{CO}_{2}$ pipeline transport significantly (workshop 1). Early insight into potential administrative costs is required to estimate the financial feasibility of CCS projects.

\subsection{Organization}

The main findings of the legislative DBS are presented in Table 7.

\subsubsection{Drivers and synergies}

- The wide experience with organizational models of natural gas pipeline projects provides valuable lessons on the design, construction and operation of pipeline infrastructures spanning national borders (Chrysostomidis and Zakkour, 2008; Mikunda et al., 2011b; Van den Broek et al., 2010; Wu and Ramírez, 2010) (interviews 1,2,3). Groenenberg and Buit (2009) distinguish three organization models, each with its own merits and demerits: public ownership, private ownership and public-private partnership (PPP). A PPP, which is an organizational model involving a contract between government and private parties to develop and operate public services, is often considered most valuable for large scale projects serving a public good, such as a future $\mathrm{CO}_{2}$ pipeline infrastructure, as it combines the safety of services due to public ownership and the working efficiency of the private sector (Groenenberg and Buit, 2009; Van den Broek et al., 2010; Wu and Ramírez, 2010).

\subsubsection{Barriers}

- The establishment of a $\mathrm{CO}_{2}$ pipeline network spanning national borders could be difficult in case there will be inconsistencies in the countries' organizational $\mathrm{CO}_{2}$ pipeline models. Experience with transboundary natural gas pipeline projects provides valuable lessons. For example, in several natural gas pipeline projects, a commission representing the governments of both countries was appointed to oversee and facilitate the resolution of transboundary issues (Interconnector, 2012). Furthermore, governments could anticipate on this issue by making multilateral agreements on tariff setting as well as by collaborating on other organizational issues for transboundary pipeline networks (Element Energy Limited, 2010b).

- Insufficient planning and communication among stakeholders and countries could result in a sub-optimal buildout, delay and increased costs of a $\mathrm{CO}_{2}$ pipeline network (Element Energy Limited, 2010b; Wu and Ramírez, 2010). Governments could prevent such a scenario by promoting efficient pipeline investment (see Section 4.3), network integration (e.g. oblige pipeline developers to provide technical possibilities for future pipeline connections) and efficient use of pipeline capacity via unbundling of ownership and operation, setting a fair tariff structure, and establishing a transparent secondary trading platform for pipeline capacity (NERA Economic Consulting, 2009a).

- Insufficient scheduling between pipeline network developers and $\mathrm{CO}_{2}$ capture operators in the industrial and power sectors could be a potential barrier (Element Energy Limited, 2010a) (interview 2 ). Working out a master plan for the deployment of a largescale CCS network in and across the WMR is, therefore, of key importance.

- The complicated relationships between different Spanish regions could make $\mathrm{CO}_{2}$ pipeline transport from one region to the other problematic. Storing one region's $\mathrm{CO}_{2}$ in another region could be perceived as waste dumping and stir up tensions. Possible solutions should focus on providing information and facilitating communication among the regions involved as well as on financial compensations from the emitter to the storage regions (interview 3).

\subsection{Route specific drivers, barriers and synergies}

\subsubsection{Synergies through utilization of existing ROW and sharing} costs between parallel pipelines

The $\mathrm{CO}_{2}$ pipeline networks in the three scenarios show several potential opportunities for legal and economic synergies by laying $\mathrm{CO}_{2}$ pipelines parallel to natural gas pipelines (see red and 
Table 8

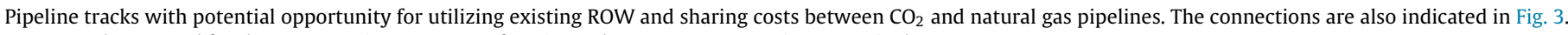
CS, CFS and FRS stand for the Conservative CCS, Cross-frontier and Free-routes scenario, respectively.

\begin{tabular}{|c|c|c|c|}
\hline Route & Connections & Scenarios & Rough estimate distance $(\mathrm{km})$ \\
\hline \multicolumn{4}{|l|}{ Spain } \\
\hline Ribadeo- Oviedo & I & CS,CFS,FRS & 100 \\
\hline Tudela-Zaragoza & II & CS,CFS,FRS & 50 \\
\hline Benlloch-Sagunt & III & $\mathrm{CS}, \mathrm{CFS}$ & 100 \\
\hline Urda-Puertollano & IV & CS,CFS,FRS & 100 \\
\hline \multicolumn{4}{|l|}{ Portugal } \\
\hline Porto-Aveiro & V & CS,CFS,FRS & 50 \\
\hline
\end{tabular}

Table 9

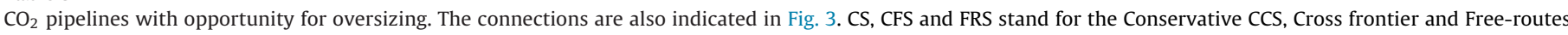
scenario, respectively.

\begin{tabular}{|c|c|c|c|}
\hline Route & Connections & Scenarios & Rough estimate distance $(\mathrm{km})$ \\
\hline \multicolumn{4}{|l|}{ Spain } \\
\hline San Sebastián-Logroño & $\mathrm{a}$ & CS,CFS,FRS & 100 \\
\hline Bilbao-San Sebastián & $\mathrm{b}$ & CS,CFS & 100 \\
\hline San Esteban de Gormaz-Andorra (city) & $\mathrm{c}$ & CS,CFS & 300 \\
\hline Barcelona-Valencia & $\mathrm{d}$ & $\mathrm{CS}, \mathrm{CFS}$ & 300 \\
\hline Aranjuez-Puertollano & $\mathrm{e}$ & CFS,FRS & 100 \\
\hline Huelva- Mengíbar & $\mathrm{f}$ & CS,FRS & 300 \\
\hline Tarragona-Escatron & $\mathrm{g}$ & CFS & 200 \\
\hline \multicolumn{4}{|l|}{ Morocco } \\
\hline Rabat- Tetouan/Ceuta & $\mathrm{h}$ & CFS & 200 \\
\hline \multicolumn{4}{|l|}{ Transboundary } \\
\hline Abrantes (Portugal)-Córdoba (Spain) & $\mathrm{i}$ & CFS & 400 \\
\hline
\end{tabular}

black lines running parallel in Figs. 2-4). However, as mentioned before, the possibility to exploit these synergies is dependent on site-specific conditions; further research is required to identify specific tracks where these synergies can be exploited. Table 8 presents a list of joint natural gas and $\mathrm{CO}_{2}$ pipeline tracks in Spain and Portugal for distances of fifty kilometers or longer. However, several other joint tracks with shorter distances $(<50 \mathrm{~km})$ can be observed in Figs. 2-4. Table 8 shows that most joint pipeline tracks were identified for all three scenarios, thus irrespective of the $\mathrm{CO}_{2}$ mitigation level, storage capacity potential and possibility of transboundary $\mathrm{CO}_{2}$ transport. No joint pipeline tracks were identified for Morocco. It should be noted that from a cost perspective following natural gas pipelines is not by definition the least cost pipeline network solution. This is shown by the investment cost of the pipeline network, which is lower in the Free-routes scenario than in the other two scenarios (see Appendix A).

\subsubsection{Oversizing of $\mathrm{CO}_{2}$ pipelines to exploit economies of scale}

Table 9 gives an overview of $\mathrm{CO}_{2}$ pipelines eligible for oversizing in the three scenarios to exploit economies of scale. The pipeline running from San Sebastián to Logroño is oversized in all three scenarios; the other pipelines are oversized in one or two scenarios. The pipelines should be oversized during the design and construction; this is before 2030 for all pipelines except for the pipeline running from Aranjuez to Puertollano, which should be in operation in 2040.

\subsubsection{Water bodies and land use planning regulations of special} areas

Water bodies and land use planning regulations pertaining to special areas result in high costs for crossing these areas or even obliges pipeline developers to make detours, which can also result in additional costs and a delay of project deployment (see Section 4.2). Water bodies and protected nature reserves are marked with blue and green areas in Figs. 2-4, respectively. An example of a pipeline crossing an estuary is the Sines-Setúbal pipeline in Portugal in the Conservative CCS and Cross-frontier scenarios in 2030, which is a protected area (Natural Reserve of the Sado Estuary); and also Parque Natural da Arrábida (where a cement plant is located). Water bodies (e.g. rivers and estuaries) are crossed several times as these are more difficult to avoid.

\subsubsection{Geographical altitude differences}

Mountain crossings are mainly observed in the Cantabrian Mountains (north of Spain) between Asturias and León, south of the province Cantabria, and between Vizcaya and Guipuzcoa (Spain) in the Conservative CCS and Cross-frontier scenarios; in the Free-routes scenario, mountain crossings are observed between San Sibrao and Ponferrada in León, and Vizcaya and Alava (see Table 10). Installation and operation of $\mathrm{CO}_{2}$ pipelines and power supply will be expensive along these $\mathrm{CO}_{2}$ pipeline tracks.

Table 10

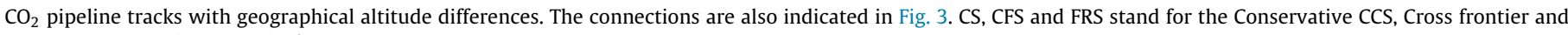
Free-routes scenario, respectively.

\begin{tabular}{|c|c|c|c|}
\hline Route & Connections & Scenarios & Rough estimate distance $(\mathrm{km})$ \\
\hline \multicolumn{4}{|l|}{ Spain } \\
\hline Asturias-León & 1 & CS,CFS & 100 \\
\hline Vizcaya-Guipuzcoa & 2 & CS,CFS & 100 \\
\hline South of Cantabria & 3 & CS,CFS & 50 \\
\hline San Sibrao-Ponferrada & 4 & FRS & 50 \\
\hline Vizcaya-Alava & 5 & FRS & 50 \\
\hline
\end{tabular}




\section{Discussion}

The research resulted in a comprehensive list of DBS that is considered to be quite exhaustive, because of the various ways of data collection. For this reason, the method proved to be an effective way to identify DBS for a pipeline infrastructure. However, a caveat is issued in relation to the route-specific DBS, which depend strongly on the pipeline modelling results and are thus rather uncertain. Despite this generic uncertainty, several pipeline routes occur in all three scenarios and are, therefore, likely to be installed in case CCS is deployed at a large scale across the region. Further research should aim to identify for which parts of these pipeline routes, ROW can already be acquired, and, if sufficient space is available in the pipeline corridors, where ROW of natural gas pipelines can be used for the $\mathrm{CO}_{2}$ pipelines to avoid unnecessary delays and exploit cost synergies. Albeit crossings of mountains, nature areas and water bodies were discouraged in the modelling work, several crossings can be observed in the pipeline networks (see Section 4.5). Where possible, alternative routes could be considered on a case-by-case basis; for example, by deviating from the natural gas pipeline tracks in the CS and CFS scenarios, several barriers can be avoided (see Section 4.5). Furthermore, in due time, assessments should be made for which $\mathrm{CO}_{2}$ trunk pipelines that show opportunities for capacity oversizing to exploit economies of scale (e.g. between San Sebastián to Logroño in the north of Spain), oversizing is indeed economically interesting. To this end, the $\mathrm{CO}_{2}$ pipeline design criteria of Knoope et al. (2014a) could be used, which allows for a more detailed techno-economic optimization analysis of $\mathrm{CO}_{2}$ pipeline configurations, including pipeline oversizing. Next to the route-specific DBS, several other issues were identified that merit further research:

- In the COMET model, the contribution of the individual $\mathrm{CO}_{2}$ source clusters to the national sector emissions were assumed to remain constant over the modelling period. More insight is needed on the development of cluster development as well as on the advent and location of new industries to improve the modelling of sector emissions and pipeline networks. Similarly, exploration of the $\mathrm{CO}_{2}$ storage sites is required at an early stage to validate the values used in the COMET model for the characteristics (e.g. injection rate) and potential of the individual sites.

- The data collection in Morocco was rather difficult. More research is needed to identify potential remaining DBS in Morocco and validate the country specific DBS for the Moroccan case, especially by studying analogue pipeline trajectories and doing interviews with local stakeholders. Although the modeling results of (Kanudia et al., 2013, 2012c,d) show only few $\mathrm{CO}_{2}$ pipelines in Morocco (Figs. 2-4), more could follow in case further research would confirm expectations on the large offshore $\mathrm{CO}_{2}$ storage potential, which is currently unknown due to limited (publicly) available data (Martínez and Carneiro, 2011).

- Albeit offshore and transboundary pipeline transport plays only a minor role in the modelled pipeline networks, it is recommended to anticipate on potential DBS related to these topics, such as cross-jurisdictional issues, by investigating them beforehand. Improved input data quality for the COMET model, including on the storage potential on the Moroccan continental shelf and other parts of North Africa, could result in more offshore and transboundary pipeline transport, thereby making these topics more relevant.

- Geske et al. (2015a,b) show that $\mathrm{CO}_{2}$ shipping can be a cost effective alternative for certain offshore pipeline routes, especially for transport of small volumes and over long distances. Furthermore, ships have the advantage of flexibility, which could be especially interesting in the early stages of the CCS market. Therefore, the
DBS of the $\mathrm{CO}_{2}$ shipping option should be further investigated to explore the practical feasibility of this transport mode.

- Ways to engage the local public, politics and NGOs in the process of designing the CCS infrastructure should be assessed so that their points of view can be optimally incorporated in this process (see e.g. Terwel et al., 2012). Further research is desirable to identify fruitful modes of engagement.

\section{Conclusions}

\section{Conclusions}

This study provided a method to identify drivers, barriers and synergies (DBS) related to the deployment of a regional $\mathrm{CO}_{2}$ pipeline network. The method was demonstrated for the West Mediterranean region (WMR) and is related to other research carried out in the COMET project (Boavida et al., 2013; Gouveia et al., 2013; Kanudia et al., 2013; Van den Broek et al., 2013b), in which several possible $\mathrm{CO}_{2}$ pipeline networks were modelled under three scenarios that differed with respect to: (i) whether $\mathrm{CO}_{2}$ pipelines should follow existing pipelines (mainly natural gas) where available (Conservative CCS and Cross-frontier scenario), or not (Free-routes scenario), and (ii) on the possibility to transport $\mathrm{CO}_{2}$ across national borders (Cross-frontier scenario) or to restrict $\mathrm{CO}_{2}$ transport to the country level (Conservative CCS and Freeroutes scenarios).

The first part of the method comprised a literature review, an analysis of embedded hydrocarbon and $\mathrm{CO}_{2}$ pipeline trajectories, interviews with pipeline experts, and workshops with stakeholders. Subsequently, the collected information was used to identify route specific DBS in the modelled $\mathrm{CO}_{2}$ pipeline networks. Finally, where applicable actions were identified that could alleviate the barriers or take advantage of the synergies and drivers. The research resulted in a comprehensive list of DBS for the WMR case study, which is expected to be quite exhaustive, because of the various ways of data collection. Furthermore, the list provides a framework for action. For these reasons, the method proves to be an effective way to identify DBS for a pipeline infrastructure, also in other parts of the world.

Based on the WMR case study an extensive list of DBS has been compiled. The identified barriers can in principle be tackled to make the design, construction and operation of $\mathrm{CO}_{2}$ pipeline network possible. Furthermore, there are opportunities for cost reductions and facilitating processes as well. Most of the DBS can and should be addressed at an early stage to enable $\mathrm{CO}_{2}$ pipeline transport in the future. The DBS are related to $\mathrm{CCS}$ and $\mathrm{CO}_{2}$ pipeline transport in general as well as to the specific pipeline routes in the modelled scenarios.

The main drivers/synergies identified in both literature and by local stakeholders applying to $\mathrm{CO}_{2}$ pipeline networks in general are the long experience with natural gas pipeline transport, embedded legislation, existing investment and organizational models for hydrocarbon pipeline networks, and oversizing pipelines to exploit economies of scale. Portuguese and Spanish stakeholders added that earmarking $\mathrm{CO}_{2}$ pipeline ventures as public interest projects can expedite the implementation of $\mathrm{CO}_{2}$ pipeline projects. Most route specific drivers and synergies apply to all three scenarios, although not always to the same extent. The $\mathrm{CO}_{2}$ sources and sinks in the WMR are located far from each other. There are several opportunities to lay $\mathrm{CO}_{2}$ pipelines along existing pipelines, provided sufficient space is available in the pipeline corridors, thus creating opportunities to reduce costs and utilize existing Right of Way. However, the Free-routes scenario shows that it is not necessarily cheaper to follow natural gas pipelines, because deviating from the natural gas pipelines can reduce the $\mathrm{CO}_{2}$ pipeline distances 
considerably. These cost considerations may affect the eventual routing of the pipeline networks. Another potential synergy can be achieved by oversizing (trunk) $\mathrm{CO}_{2}$ pipelines to exploit economies of scale in case the oversized capacity is used not later than five to ten years after the construction of the pipeline.

The main technological barriers applying to $\mathrm{CO}_{2}$ pipeline networks in general are the knowledge gaps on the (cost increasing) effect of impurities and intermittent flow patterns on the physicochemical properties of the $\mathrm{CO}_{2}$ flow during pipeline transport as well as on the probability and impact of a $\mathrm{CO}_{2}$ pipeline failure. Other main barriers are the lack of specific legislation on $\mathrm{CO}_{2}$ pipeline transport, lengthy permit procedures, land use planning regulations, uncertainty of future climate policy, lack of financial incentives, high level and risk profile of $\mathrm{CO}_{2}$ pipeline investments, the economic crisis, and the need for an electric infrastructure to power booster stations. The technical and economic route specific barriers relate to crossings of water bodies and mountainous areas as well as land use planning regulations of special areas. The Crossfrontier scenario shows specific barriers related to unresolved issues in international conventions (e.g. London Protocol and Basel Convention) and different jurisdictions and organizational models of transport networks between countries, which currently hamper transboundary $\mathrm{CO}_{2}$ transport. Although many barriers were identified, most of these barriers (e.g. technical knowledge gaps, outstanding legislative issues, lack of financial incentive) can, in principle, be tackled.

\subsection{Policy implications}

Most DBS identified in this study are generic, i.e. they apply to $\mathrm{CO}_{2}$ pipeline transport in general and are not route specific. The DBS list provides a framework for action comprising short term measures related to different aspects of pipeline infrastructure, namely technology (i), legislation/policy (ii, iii), economics/finance (iv, v) and organization (vi). The key measures are: (i) stimulating research and CCS demonstration projects to investigate remaining technical knowledge gaps (e.g. effect of impurities in and intermittency of $\mathrm{CO}_{2}$ flows) and prove the techno-economic feasibility of CCS; (ii) formulating consistent and transparent policy regarding CCS; (iii) resolving outstanding legal issues in international treaties and establishing a transparent national and regional (preferably on EU level) legislative framework to enable $\mathrm{CO}_{2}$ pipeline transport. Concerted action and involvement of private and public stakeholders (also between countries) are key to create a broadly supported and coherent legislative framework; (iv) establishing a (European wide), well-functioning financial regulatory framework (e.g. ETS or a carbon tax) to make a sound business case for CCS possible; (v) devising financial programs to supply potential investors in $\mathrm{CO}_{2}$ pipeline infrastructure with funding resources and low risk exposure; (vi) scheduling and communication among stakeholders and countries involved in different parts of the CCS chain to avoid delay and sub-optimal infrastructure deployment.

The route specific DBS in the WMR case study are more relevant for the mid-long term. Mid-long term measures should focus on the preparation of public utility declarations and permits for the crossings of nature reserves, the acquisition of ROW and pipeline oversizing. More research is needed to identify for which parts of the identified pipeline routes these measures should be taken.

\section{Acknowledgements}

This research has been carried out in the context of the EU funded COMET project. The authors gratefully acknowledge $\mathrm{Mr}$. Paulo Mesquita (University of Évora) for his aid with the drawing of the maps of the Iberian Peninsula and Morocco.

\section{Appendix A. West Mediterranean region}

This appendix describes the case study of the Iberian Peninsula and Morocco that was used for the analysis in this paper.

\section{West Mediterranean region}

The WMR shows potential for CCS considering its large $\mathrm{CO}_{2}$ storage capacity, especially in Spain (GCCSI, 2012). An inventory was made of the $\mathrm{CO}_{2}$ point sources and storage locations across the WMR by Boavida and Sardinha (2012), Boavida et al. (2012a), Martínez and Carneiro (2011).

The map in Fig. A1 shows the 285 stationary $\mathrm{CO}_{2}$ point sources across the region over the period 2005-2009. The point sources are made up of utilities, oil refineries, cement, iron and steel, pulp and paper and other industries. Note that Spain accounts for more than $70 \%$ of the point sources (221) and $\mathrm{CO}_{2}$ emissions $\left(153 \mathrm{MtCO}_{2} / \mathrm{y}\right)$ in the three countries. The Spanish point sources are spread all over the country. Portugal and Morocco show similar features in number of point sources ( 35 and 29 , respectively) and emitted $\mathrm{CO}_{2}$ (both around $28 \mathrm{MtCO}_{2} / \mathrm{y}$ ) (Mesquita and Carneiro, 2013). Both the Portuguese and Moroccan point sources are predominantly located in the coastal areas.

The map in Fig. A2 provides an overview of the locations and storage potential of the $\mathrm{CO}_{2}$ injection sites across the WMR. The total storage capacity amounts to nearly $30 \mathrm{GtCO}_{2}$, which is divided over a number of 163 storage structures. Spain has the largest estimated storage capacity (around $22 \mathrm{GtCO}_{2}, 118$ structures), followed by Portugal ( $7.5 \mathrm{GtCO}_{2}, 36$ structures) and Morocco $\left(0.4 \mathrm{GtCO}_{2}, 9\right.$ structures) (Mesquita et al., 2013). Storage structures with a capacity less than $3 \mathrm{MtCO}_{2}$ were excluded from the inventory, nor are they shown in Fig. A2.

\section{Scenarios and $\mathrm{CO}_{2}$ pipeline networks for the West Mediterranean region}

Eight scenarios were devised for the WMR for the time period 2010-2050 with different assumptions on gross domestic production (GDP) growth and concomitant $\mathrm{CO}_{2}$ emissions, $\mathrm{CO}_{2}$ emission reduction levels, $\mathrm{CCS}$ availability, storage potential, $\mathrm{CO}_{2}$ pipeline networks, and the possibility to transport $\mathrm{CO}_{2}$ across country borders (see Gouveia et al., 2013). For the design of the pipeline networks, both the $\mathrm{CO}_{2}$ point sources and sinks were clustered together to reduce the number of pipelines and exploit economies of scale (see Figs. A1 and A2). The hubs of the source and sink clusters were connected in a most cost effective way for each scenario.

Three of the eight aforementioned scenarios differ with respect to assumptions made on the $\mathrm{CO}_{2}$ pipeline network; hence, the focus in this study was on these three scenarios. The assumptions differ on (1) whether $\mathrm{CO}_{2}$ pipelines should follow existing pipelines (mainly natural gas) where available (Conservative CCS and Crossfrontier), or not (Free-routes), and (2) on the possibility to transport $\mathrm{CO}_{2}$ across national borders (Cross-frontier) or to restrict $\mathrm{CO}_{2}$ transport to the country level (Conservative CCS and Free-routes). These three scenarios assume an annual GDP growth over the coming forty years (Spain: 2.4\%/y; Portugal: $2.0 \% / y$; Morocco: $3.6 \% / y)^{8}$, a national $\mathrm{CO}_{2}$ emission target of $40 \%$ below 2005 levels in 2050, and the technical and economic availability of CCS from 2020 onwards.

\footnotetext{
8 The annual GDP growth rates were mainly based on projections of the International Monetary Fund (IMF, 2012). However, the projections for Spain and Portugal could be regarded as too optimistic considering the current economic crisis. In the COMET model, a scenario with a low GDP growth was run as well (see Kanudia et al., 2013). It was found that with low economic growth assumptions CCS remains competitive but the market is reduced.
} 


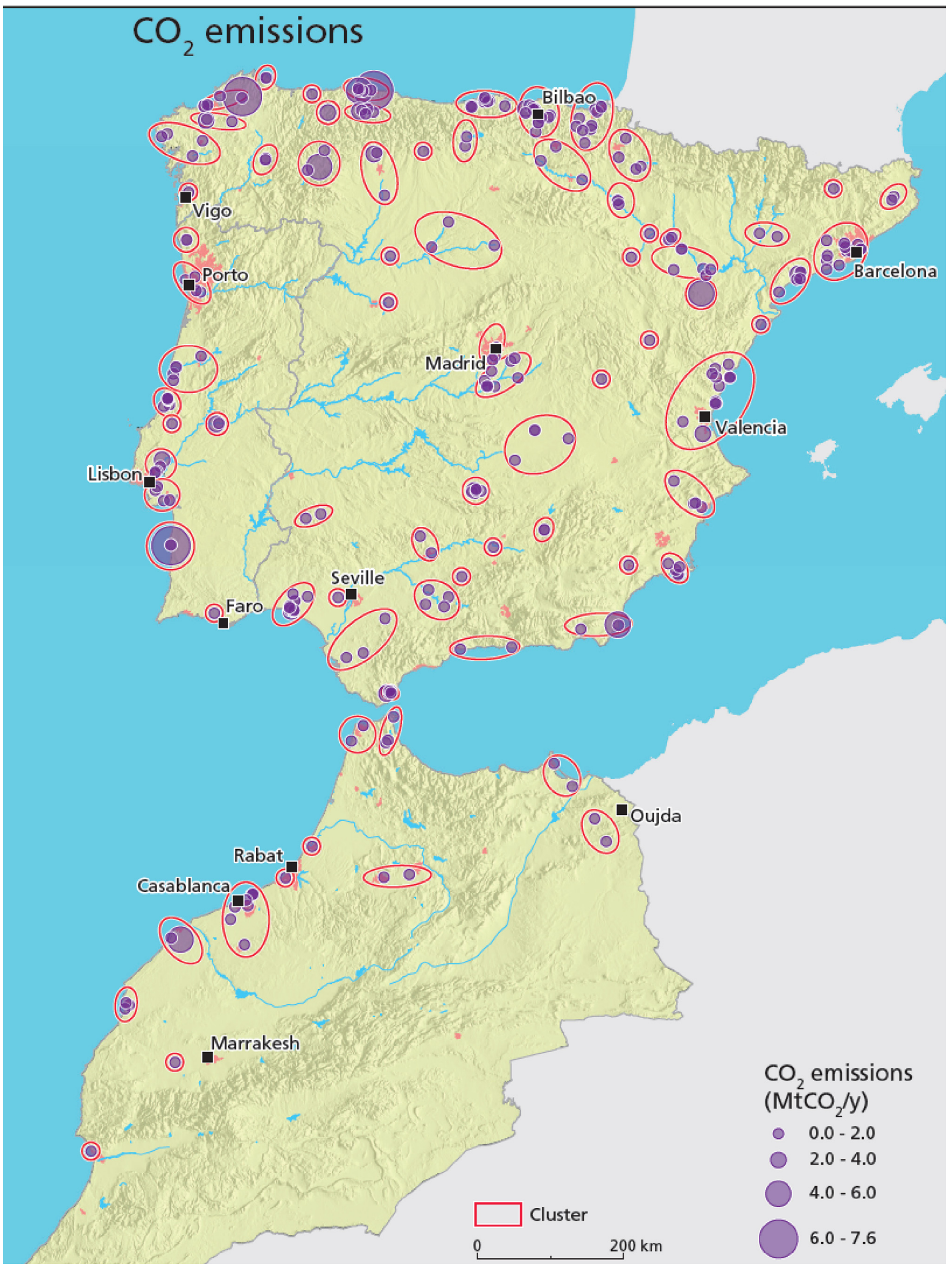

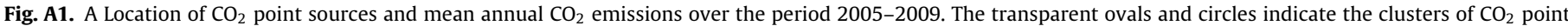
sources used for the modelling exercise. 


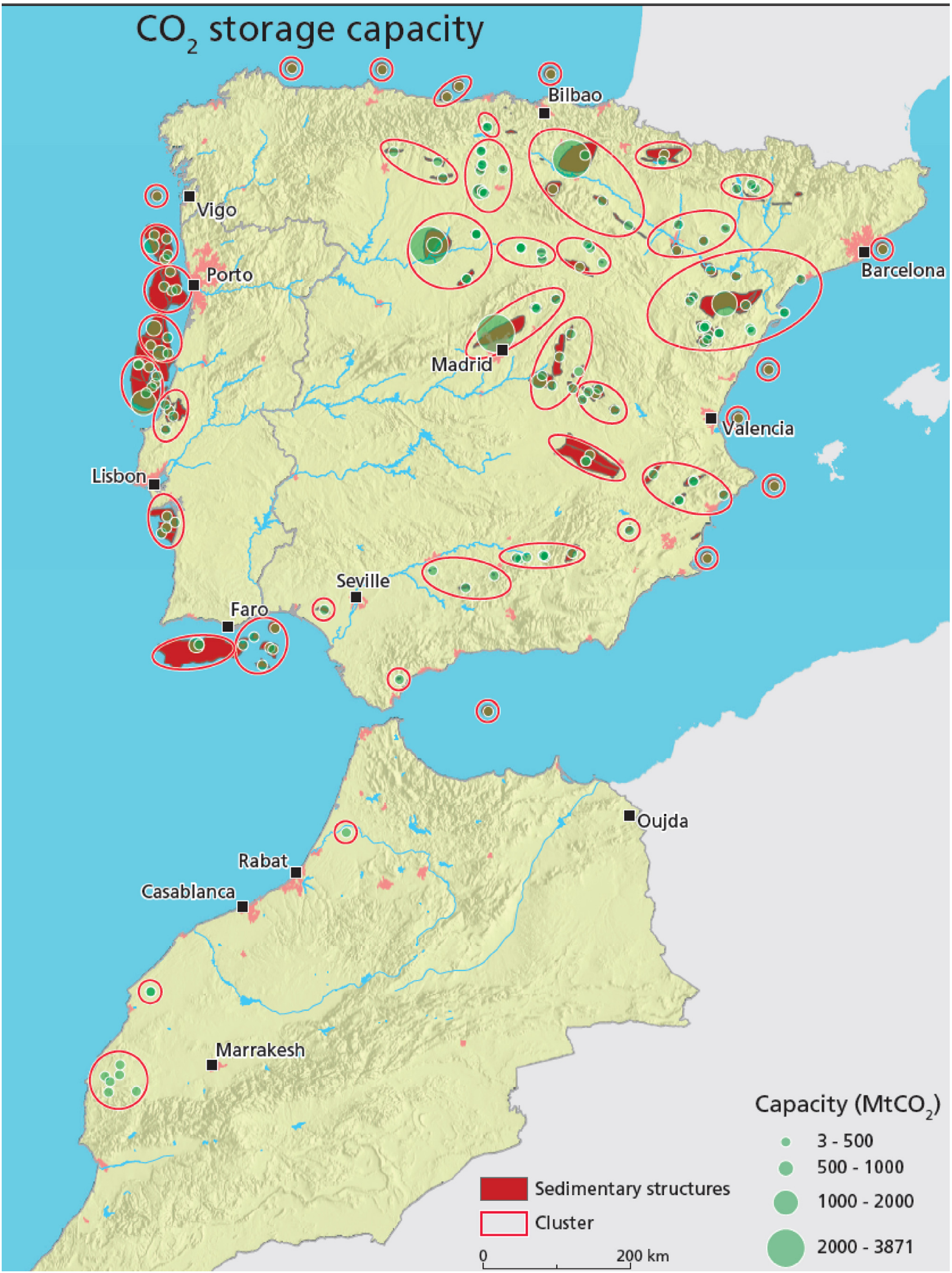

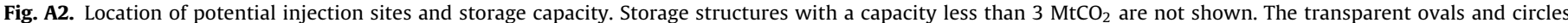
indicate the clusters of sinks used for the modelling exercise. 
Table A1

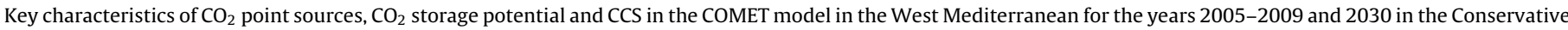
CCS, Cross-frontier and Free-routes scenarios.

\begin{tabular}{|c|c|c|c|}
\hline & Spain & Portugal & Morocco \\
\hline \multicolumn{4}{|l|}{ General } \\
\hline $\mathrm{CO}_{2}$ point sources ${ }^{\mathrm{a}}(\mathrm{nr})$. & 221 & 35 & 29 \\
\hline Point source clusters ${ }^{\mathrm{b}}$ (nr.) & 44 & 10 & 12 \\
\hline Storage structures ${ }^{c}(\mathrm{nr})$. & 118 & 36 & 9 \\
\hline Storage potential ${ }^{\mathrm{c}}\left(\mathrm{GtCO}_{2}\right)$ & 22 & 7.5 & 0.4 \\
\hline Storage clusters ${ }^{\mathrm{b}}$ (nr.) & 28 & 8 & 4 \\
\hline \multicolumn{4}{|l|}{ 2005-2009 } \\
\hline $\mathrm{CO}_{2}$ emissions $^{\mathrm{a}}\left(\mathrm{MtCO}_{2} / \mathrm{y}\right)$ & 153 & 28 & 28 \\
\hline \multicolumn{4}{|l|}{2030} \\
\hline $\mathrm{CO}_{2}$ emissions w/o capture $\left(\mathrm{MtCO}_{2} / \mathrm{y}\right)$ & 365 & 51 & 86 \\
\hline $\mathrm{CO}_{2}$ captured $^{\mathrm{d}}\left(\mathrm{MtCO}_{2} / \mathrm{y}\right)$ & 50 & 5 & 3 \\
\hline $\mathrm{CO}_{2}$ emissions after capture $\left(\mathrm{MtCO}_{2} / \mathrm{y}\right)$ & 327 & 47 & 84 \\
\hline $\mathrm{CO}_{2}$ avoided via $\mathrm{CCS}\left(\mathrm{MtCO}_{2} / \mathrm{y}\right)$ & 38 & 4 & 3 \\
\hline
\end{tabular}

a Point sources emitting less than 0.08 MtCO2/y were excluded from the inventory (Boavida and Sardinha, 2012; Boavida et al., 2012a; Martínez and Carneiro, 2011). ${ }^{\text {The }}$

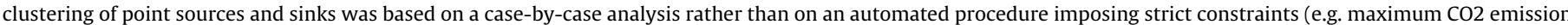

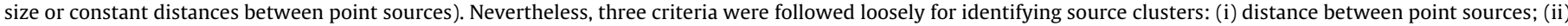

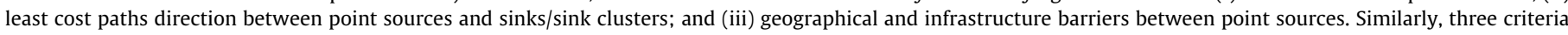

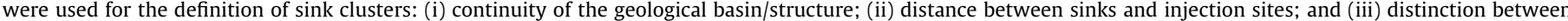

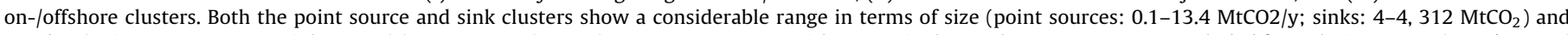

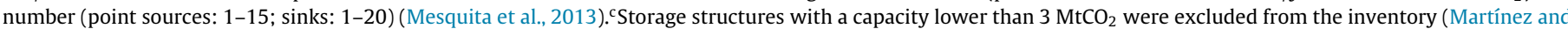

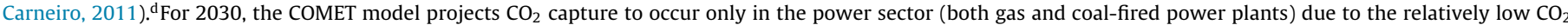

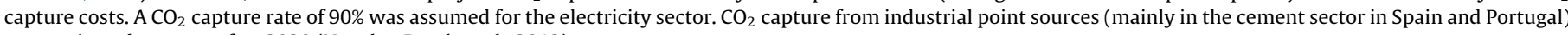
was projected to occur after 2030 (Van den Broek et al., 2013).

The DBS identified in the literature review and country analyses were assessed for the $\mathrm{CO}_{2}$ pipeline networks simulated for these three scenarios. The assessment was done for the $\mathrm{CO}_{2}$ pipeline networks in the year 2030 (instead of 2050) as this will result in a lower uncertainty in the scenario parameters, pipeline networks configurations, and thus, route specific DBS.

Table A1 gives an overview of the key characteristics of the $\mathrm{CO}_{2}$ sources, storage potential and CCS for the three scenarios in the WMR for the years 2005-2009 and 2030. Figs. 2-4 in Section 3 show the $\mathrm{CO}_{2}$ pipeline networks for the Conservative CCS, Cross-frontier and Free-routes scenarios for the year 2030, respectively.

As can be seen in Figs. 2 and 3, the $\mathrm{CO}_{2}$ pipeline networks in the Conservative CCS and Cross-frontier scenarios in 2030 are rather similar; this is mainly because in both scenarios the $\mathrm{CO}_{2}$ pipelines have to follow the existing natural gas pipeline network. The key differences are the transboundary pipelines in the Crossfrontier scenario: between Vigo (north of Spain) and Porto (north of Portugal), between Abrantes (center of Portugal) and Córdoba (southwest Spain), and between Algeciras (south of Spain) and Ceuta/Tetouan (north of Morocco). Nevertheless, transboundary transport seems to play a limited role in the future $\mathrm{CO}_{2}$ pipeline networks. Another notable difference is the pipeline network along the Moroccan coast, which emerges in the northwest in the Crossfrontier scenario as a result of the opportunity to store Moroccan $\mathrm{CO}_{2}$ in low-cost Spanish storage reservoirs, instead of in the west of Morocco where storage sites are more expensive. The Freeroutes scenario shows significantly more differences compared to the other two scenarios, mainly due to the freedom in pipeline routing, which resulted in more direct $\mathrm{CO}_{2}$ pipeline connections, especially in Spain. Also, whereas the Free-routes scenario shows three separate pipeline networks within Spain, the Conservative CCS and Cross-frontier scenario display a more integrated network within the country.

Figs. 2-4 show merely one offshore pipeline (AlgecirasCeuta/Tetouan), which is used for transboundary transport in the Cross-frontier scenario (Fig. 3) rather than for offshore storage. In 2030, the backbone of the $\mathrm{CO}_{2}$ pipeline network across the region is already in place and has a length of around $5.5 \times 10^{3} \mathrm{~km}$ in all three scenarios (compared to around $7.9 \times 10^{3} \mathrm{~km}$ in 2050) (Van den Broek et al., 2013a). Therefore, most of the investments in trunk pipelines will be needed in the period up to 2030. In the Conservative CCS scenario, pipeline investments amount up to 3.9 billion euro out of 4.6 billion in 2050 . The Free-routes scenario shows that investments cost ( 0.6 billion euro in 2020) may be significantly lower compared to the Conservative CCS scenario (1.4 billion euro in 2020) while being able to store the same amount of $\mathrm{CO}_{2}$, owing to the high degree of freedom in selecting pipeline routes. Investment cost could be substantially reduced (around 0.9 billion euro) by postponing a number of pipelines which are oversized for the period after 2030 (Van den Broek et al., 2013a).

\section{Appendix B.}

Table B1 gives an overview of the main technical features of the study of analogue pipeline trajectories used for this study. More detailed information on technical, legal, financial and organizational aspects can be found in COMET $(2012 a, b, c)$ as well as in the references presented in Table B1. 
Table B1

Overview of main technical features of the analogue pipeline trajectories used for this study.

\begin{tabular}{|c|c|c|c|c|c|c|c|}
\hline & Sines-Setubal & $\begin{array}{l}\text { Sines-Aveiras de } \\
\text { Cima }\end{array}$ & Setubal-Braga & Braga-Tuy & $\begin{array}{l}\text { Leiria-Campo } \\
\text { Maior }\end{array}$ & MEDGAZ & Compostilla \\
\hline Sources & $\begin{array}{l}\text { Hidroprojecto } \\
\text { (2001) }\end{array}$ & $\begin{array}{l}\text { Agripo Ambiente } \\
\text { (1995) }\end{array}$ & $\begin{array}{l}\text { SEIA (1995a,b, } \\
\text { 1994) }\end{array}$ & IMPACTE $(1997,1996)$ & REN (2007) & $\begin{array}{l}\text { Mikunda et al. } \\
\text { (2011b) }\end{array}$ & $\begin{array}{l}\text { Compostilla Project } \\
(2013)\end{array}$ \\
\hline Transported matter & Natural gas & $\begin{array}{l}\text { Refined oil } \\
\text { products }\end{array}$ & Natural gas & Natural gas & Natural gas & Natural gas & $\mathrm{CO}_{2}$ \\
\hline On-/offshore & Onshore & Onshore & Onshore & Onshore & Onshore & On- and offshore & Onshore \\
\hline Route & Sines-Setubal & Sines-Aveiras & Setubal-Braga & Braga-Tuy & $\begin{array}{l}\text { Campo } \\
\text { Maior-Leiria }\end{array}$ & $\begin{array}{l}\text { Beni Saf } \\
\text { (Algeria)-Almeria } \\
\text { (Spain) }\end{array}$ & $\begin{array}{l}\text { Compostilla-Santa } \\
\text { María del Monte de } \\
\text { Cea }\end{array}$ \\
\hline Transboundary & No & No & No & Yes & No & Yes & No \\
\hline Project start & Not indicated & 1996 & Not indicated & 1997 & Not indicated & 2006 & Not finished yet ${ }^{a}$ \\
\hline Start year operation & 2003 & 1996 & 1997 & 1997 & 1997 & 2008 & Not finished yet ${ }^{a}$ \\
\hline Length pipeline $(\mathrm{km})$ & 87 & 147 & 580 & 76 & 220 & 210 & 140 \\
\hline Diameter pipeline (inch) & 32 & 16 & Apr-28 & 20 & 28 & 24 & 14 \\
\hline Capacity $\left(10^{9} \mathrm{~m}^{3} / \mathrm{yr}\right)$ & 6 & 0.2 & 3.7 & 0.6 & 3.7 & 8 & 0.001 \\
\hline Operating pressure (bar) & 84 & 99 & $36-85$ & $36-85$ & $36-85$ & 81 & 180 \\
\hline Materials pipeline & CS API 5L X70 & CS API 5L Grx65 & CS API 5L X70 & CS API 5L X70 & CS API 5L X70 & Welded steel & CS API 5L Grx65 \\
\hline Coating & Not indicated & Not indicated & $\mathrm{PE}$ & $\mathrm{PE}$ & $\mathrm{PE}$ & PP anti-corrosion & $\mathrm{PE}$ \\
\hline Crossed terrains & $\begin{array}{l}\text { Industrial, forest, } \\
\text { agricultural, } \\
\text { populated }\end{array}$ & $\begin{array}{l}\text { Industrial, forest, } \\
\text { agricultural, } \\
\text { populated }\end{array}$ & $\begin{array}{l}\text { Flat, agricultural, } \\
\text { forestry, populated }\end{array}$ & $\begin{array}{l}\text { Agricultural, industrial, } \\
\text { forestry, populated }\end{array}$ & $\begin{array}{l}\text { a.o. crop fields and } \\
\text { pasture }\end{array}$ & Not indicated & $\begin{array}{l}\text { Sandstone, slate, } \\
\text { clay, marl }\end{array}$ \\
\hline Follows other tracks & Yes $(65 \mathrm{~km})$ & Yes & No & No & No & No & Yes, for $17 \mathrm{~km}$ \\
\hline River crossings & Yes & Yes & Yes & Yes & Not indicated & Yes (2) & Yes \\
\hline Road crossings & Yes & Yes & Yes & Yes & Not indicated & Yes (18) & Yes \\
\hline Railways & Yes & Yes & Yes & Yes & Not indicated & No & Yes \\
\hline Monitoring system & $\begin{array}{l}\text { Supervision/control } \\
\text { centres; } \\
\text { inspections by foot } \\
\text { (each } 3 \text { months) } \\
\text { and by helicopter } \\
\text { (each } 6 \text { months) }\end{array}$ & $\begin{array}{l}\text { System remote } \\
\text { control from } \\
\text { control centre; } \\
\text { volume } \\
\text { measuring + leak } \\
\text { detection system; } \\
\text { surveillance by foot } \\
\text { and helicopter; } \\
\text { PIGs }^{c}\end{array}$ & $\begin{array}{l}\text { System for supervi- } \\
\text { sion + control } \\
\text { transport network; } \\
\text { aerial, car and foot } \\
\text { patrol are regularly } \\
\text { carried out; PIGs }\end{array}$ & $\begin{array}{l}\text { Control } \\
\text { system;surveillance } \\
\text { pipeline; cathodic } \\
\text { protection; optical } \\
\text { cable along pipeline for } \\
\text { information }\end{array}$ & $\begin{array}{l}\text { Border station that } \\
\text { monitors gas } \\
\text { imports }\end{array}$ & Yes & Not indicated \\
\hline $\begin{array}{l}\text { Technical difficulties with } \\
\text { construction }\end{array}$ & $\begin{array}{l}\text { Crossing protected } \\
\text { areas; } 5 \mathrm{~m} \text {. distance } \\
\text { between pipeline } \\
\text { axes required } \\
\text { when crossing } \\
\text { rivers or lakes }\end{array}$ & $\begin{array}{l}\text { Crossing protected } \\
\text { areas (Sado river); } \\
\text { establishment } \\
\text { ROW; risks related } \\
\text { to infrastructure } \\
\text { building }\end{array}$ & $\begin{array}{l}\text { Crossing obstacles; } \\
\text { digging } \\
\text { restrictions; } \\
\text { minimum } \\
\text { distances from } \\
\text { constructions and } \\
\text { vegetation }\end{array}$ & $\begin{array}{l}\text { Crossings protected } \\
\text { areas + water bodies; } \\
\text { use explosions in rocky } \\
\text { areas; impact on } \\
\text { environment }\end{array}$ & Not indicated & $\begin{array}{l}\text { Changes in } \\
\text { topography, } \\
\text { crossing natural } \\
\text { parks and other } \\
\text { protected areas }\end{array}$ & Not indicated \\
\hline $\begin{array}{l}\text { Technical difficulties with } \\
\text { operation }\end{array}$ & Not indicated & Not indicated & $\begin{array}{l}\text { Compression, } \\
\text { maintenance, } \\
\text { monitoring, } \\
\text { corrosion, pressure } \\
\text { drops, } \\
\text { intermittency }\end{array}$ & Not indicated & Not indicated & $\begin{array}{l}\text { Onshore patrolling } \\
\text { of route difficult in } \\
\text { areas with low } \\
\text { accessibility }\end{array}$ & Not indicated \\
\hline
\end{tabular}

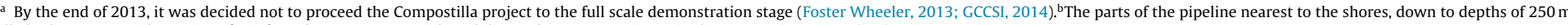

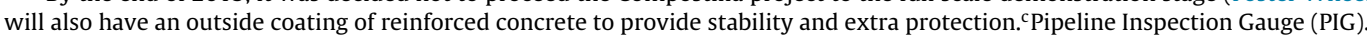


Table C1

Stakeholders present at workshops in Spain, Portugal and Morocco.

\begin{tabular}{|c|c|c|}
\hline Spain & Portugal & Morocco \\
\hline ENDESA (energy company) & REN-Gasodutos S.A. (energy company) & SAMIR (refinery company) \\
\hline ENAGÁS (natural gas company) & Galp Energia S.A. (natural gas company) & $\begin{array}{l}\text { CNRST (National center for scientific research } \\
\text { and technology) }\end{array}$ \\
\hline Gas Natural Fenosa (energy company) & ENDESA (Spanish energy company) & $\begin{array}{l}\text { OREDDO (regional observatory for } \\
\text { environmental and sustainable development } \\
\text { of the East) }\end{array}$ \\
\hline Iberdrola (energy company) & $\begin{array}{l}\text { EDP (Energy production management } \\
\text { corporation) }\end{array}$ & National Moroccan phosphate company \\
\hline ELCOGAS, S.A. (IGCC power plant) & Tejo Energía, S.A. (energy company) & GPower Consultants \\
\hline Repsol S.A. (oil and gas company) & CIMPOR (cement producer) & $\begin{array}{l}\text { ADEREE (Agency for the development of } \\
\text { renewable energy and energy efficiency) }\end{array}$ \\
\hline UNESA (Spanish Association of the Power Industry) & $\begin{array}{l}\text { DGEG (Directorate-General for Energy and } \\
\text { Geology) }\end{array}$ & $\begin{array}{l}\text { Managem (mining and hydro metallurgy } \\
\text { group) }\end{array}$ \\
\hline Spanish $\mathrm{CO}_{2}$ platform & $\begin{array}{l}\text { CECAC (Executive Committee of the Climate } \\
\text { Change Commission) }\end{array}$ & National office of electricity \\
\hline $\begin{array}{l}\text { CEOE (Commission of Energy in the Spanish Confederation } \\
\text { of Employers' Organizations) }\end{array}$ & $\begin{array}{l}\text { QUERCUS (National Association for Nature } \\
\text { Conservation) }\end{array}$ & $\begin{array}{l}\text { ONHYM (Moroccan Office of Hydrocarbons and } \\
\text { Mining) }\end{array}$ \\
\hline OECC (Spanish Office of Climate Change) & $\begin{array}{l}\text { DGPM (Directorate-General for regional } \\
\text { policies) }\end{array}$ & Transcarbon (consultant) \\
\hline Oil and Gas Capital (Hydrocarbons' Prospecting company) & Royal Norwegian Embassy & Ministry of energy, mines and water \\
\hline $\begin{array}{l}\text { ISOLUX CORSAN, S.A. (Global benchmark in the areas of } \\
\text { concessions energy, construction and industrial services) }\end{array}$ & $\begin{array}{l}\text { LNEG (National laboratory of energy and } \\
\text { geology) }\end{array}$ & Ministry of Environment \\
\hline IPF (Petrophysical Institute Foundation) & $\begin{array}{l}\text { FFCT (New University of Lisbon-Faculty of } \\
\text { Science and Technology) }\end{array}$ & University Al Akhawayn \\
\hline CIUDEN (Energy City Foundation) & UEVORA (University of Évora) & University of Rabat \\
\hline Air Liquide (industrial gas producer) & & University of Mohammed 1st \\
\hline \multicolumn{3}{|l|}{$\begin{array}{l}\text { CIEMAT (Spanish National Research Centre for Energy, } \\
\text { Environment and Technology) }\end{array}$} \\
\hline \multicolumn{3}{|l|}{$\begin{array}{l}\text { IIMAC (Climate Change, Environmental and Energy } \\
\text { Consulting company) }\end{array}$} \\
\hline \multicolumn{3}{|l|}{ IGME (Spanish institute for geology \& mining) } \\
\hline Ministry of Industry, Energy and Tourism & & \\
\hline
\end{tabular}

\section{Appendix C.}

Table C1 gives an overview of the (local) stakeholders who attended the workshops in Spain, Portugal and Morocco.

Table C1 (Foster Wheeler, 2013; GCCSI, 2014).

\section{References}

AICEP, 2008. Gas sector-Infrastructures and Accessibility. Agency for Trade and Investment, Lisbon (Portugal).

Agripo Ambiente, 1995. Oleoduto multiproduto da companhia logística de combustiveis (multiproduct oil pipeline of CLC). In: Environmental Impact Assessment no 315. Agripo Ambiente-Consultores, S.A. CLC-Companhia Logística de Combustíveis, SA.

Boavida, D., Sardinha, M., 2012. Database of $\mathrm{CO}_{2}$ Point Sources. COMET-Integrated Infrastructure for $\mathrm{CO}_{2}$ transport and storage in the west Mediterranean, Lisbon, Portugal.

Boavida, D., Guerreiro, R., Mano, A., Mendes, A., Caeiro, M., 2012a. Long List of Data Element Requirements of $\mathrm{CO}_{2}$ Point Sources. D2.1. COMET-Integrated Infrastructure for $\mathrm{CO}_{2}$ transport and storage in the west Mediterranean, Lisbon, Portugal.

Boavida, D., van den Broek, M., Cabal, H., Gastine, M., Gouveia, J.P.L., Labriet, M. Rimi, A., Seixas, J., Zarhloule, Y., 2012b. Proceedings of the National Workshops on the Analysis of Modeling Results and Selection of Most Promising Transport Networks-Technical Note 6.3. OMET-Integrated Infrastructure for $\mathrm{CO}_{2}$ transport and storage in the west Mediterranean, Lisbon, Portugal.

Boavida, D., Carneiro, J., Martinez, R., van den Broek, M., Ramirez, A., Rimi, A., Tosato, G., Gastine, M., 2013. Planning CCS Development in the West Mediterranean. In: Energy Procedia. Elsevier B.V., pp. 3212-3220, http://dx. doi.org/10.1016/j.egypro.2013.06.208

CNE, 2013. Red Básica de gas natural. Comisión Nacional de Energía (WWW Document). http://www.cne.es/cne/doc/consumidores/mapa_redgas 14022011.pdf

CNE, 2013. Instalaciones del sistema gasista. Comisión Nacional de Energía (WWW Document). http://www.cne.es/cne/contenido.jsp?id nodo $=50 \& \& \&$ keyword $=\&$ auditoria $=\mathrm{F}$

COMET, 2012a. Exploratory Interviews with Galp Energia in Deliverable 6.1-Report Containing an Analysis of the Synergies and Barriers for the Deployment of the Most Promising Transport Networks in the Iberian and Morocco Region. COMET-Integrated Infrastructure for $\mathrm{CO}_{2}$ transport and storage in the west Mediterranean, Lisbon, Portugal.

COMET, 2012b. Exploratory Interviews with REN Gasodutos, S.A. in Deliverable 6.1-Report Containing an Analysis of the Synergies and Barriers for the
Deployment of the Most Promising Transport Networks in the Iberian and Morocco Region. OMET-Integrated Infrastructure for $\mathrm{CO}_{2}$ transport and storage in the west Mediterranean, Lisbon, Portugal.

COMET, 2012c. Exploratory Interviews With ENDESA/ENAGÁS in Deliverable 6.1-Report Containing an Analysis of the Synergies and Barriers for the Deployment of the Most Promising Transport Networks in the Iberian and Morocco Region. COMET-Integrated Infrastructure for $\mathrm{CO}_{2}$ transport and storage in the west Mediterranean, Lisbon, Portugal.

Chrysostomidis, I., Zakkour, P., 2008. Assessment of the range of potential funds and funding mechanisms for $\mathrm{CO} 2$ transportation networks. In: $\mathrm{CO}_{2}$ Capture Project. Environmental Resources Management (ERM), Location: unknown.

Compostilla Project, 2013. The Compostilla Project OXYCFB300 (WWW Document). http://www.compostillaproject.es/en/ccs-technology

DECC, 2010. Developing Carbon Capture and Storage (CCS) Infrastructure: Consultation on Implementing the Third Party Access Provisions of the CCS Directive and Call for Evidence on Long Term Development of CCS Infrastructure. Department of Energy and Climate Change of the United Kingdom, London, UK.

Det Norske Veritas, 2010. Design and Operation of $\mathrm{CO}_{2}$ Pipelines. DNV RP-J202, Bærum, Norway, pp. 1-42.

EDP, 2009. Gas system in Portugal. Energias de Portugal (WWW Document). www edp.pt

ERM Iberia, S.A., 2004. Medgaz natural gas transportation system-Environmental Impact Assessment, Madrid, Spain.

Element Energy Limited, 2010a. $\mathrm{CO}_{2}$ Pipeline Infrastructure: An Analysis of Global Challenges and Opportunities. Element Energy Limited, London, UK.

Element Energy Limited, 2010b. One North Seas-A Study into North Sea Cross-border $\mathrm{CO}_{2}$ Transport and Storage. Element Energy Limited, London, UK.

Element Energy Limited, 2010c. Developing a CCS network in the Tees Valley Region. Element Energy Limited, London, UK.

European Union, 2012. Carbon Capture and Storage in the Skagerrak/kattegat Region. Final Report. Chalmers University of Technology, University of Oslo, University of Gothenburg, Tel-Tek, Telemark University College, SINTEF, Geological Survey of Denmark and Greenland (GEUS), Brussels, Belgium.

Foster Wheeler, 2013. The Compostilla Project OXYCFB300-Carbon Capture and Storage Demonstration Project Knowledge Sharing FEED Report. Foster Wheeler, ENDESA, CIUDEN, Madrid, Spain.

GCCSI, 2012. The Global Status of CCS. Global CCS Institute, Canberra, Australia

GCCSI, OXYCFB 300, 2014 Compostilla Project. Global CCS Institute (WWW Document). http://www.globalccsinstitute.com/project/oxycfb-300compostilla-project

Garrett, J., McCoy, S., 2013. Carbon capture and storage and the london protocol: recent efforts to enable transboundary $\mathrm{CO}_{2}$ transfer. In: Energy Procedia. Elsevier B.V., Paris, France, pp. 7747-7755, http://dx.doi.org/10.1016/j.egypro. 2013.06.721 
Geske, J., Berghout, N., van den Broek, M., 2015a. Cost-effective balance between $\mathrm{CO}_{2}$ vessel and pipeline transport. Part I-impact of optimally sized vessels and fleets. Int. J. Greenhouse Gas Control 36, 175-188, http://dx.doi.org/10.1016/j. ijggc.2015.01.026

Geske, J., Berghout, N., van den Broek, M., 2015b. Cost-effective balance between $\mathrm{CO}_{2}$ vessel and pipeline transport: part II-design of multimodal $\mathrm{CO}_{2}$ transport: the case of the West Mediterranean region. Int. J. Greenhouse Gas Control 33, 122-134, http://dx.doi.org/10.1016/j.ijggc.2014.12.005

Gouveia, J.P., Seixas, J., Labriet, M., Fortes, P., Gargiulo, M., 2013. Prospective scenarios for the adoption of CCS technologies in the Iberian Peninsula. Sustain. Energy Technol. Assess. 2, 31-41, http://dx.doi.org/10.1016/j.seta.2013.02.002

Groenenberg, H., Buit, M., 2009. Feasibility of a $\mathrm{CO}_{2}$ Trunk Pipeline under the North $\mathrm{Sea}-$ from the Netherlands towards $\mathrm{CO}_{2}$ Storage Reservoirs Near the Norwegian Coast. Energy Center of the Netherlands, Petten, the Netherlands.

Health and Safety Laboratory, 2009. Comparison of Risk from Carbon Dioxide and Natural Gas Pipelines RR749. Buxton, Derbyshire, UK

Hidroprojecto, 2001. Gasoduto de Transporte de Gás Natural Sines/Setúbal e Extensão do Oleoduto Sines/Aveiras a Setúbal [Gas pipeline for natural gas transportation Sines/Setubal and extension of the oil pipeline Sines/Aveiras to Setúbal]. Environmental Impact Assessment. Sociedade Portuguesa de Gás Natural e CLC - Companhia Logistica de Combustiveis. Hidroprojecto Engenharia e Gestão, S.A., Lisbon, Portugal.

ICF International, 2009. Developing a Pipeline Infrastructure for $\mathrm{CO}_{2}$ Capture and Storage: Issues and Challenges.

IEA, 2010. Energy Technology Perspectives 2010-Scenarios \& Strategies to 2050.

EA, 2011. Carbon Capture and Storage and the London Protocol: Options for Enabling Transboundary $\mathrm{CO}_{2}$ Transfer. Working Paper. International Energy Agency, Paris, France.

IEA, 2012. A Policy Strategy for Carbon Capture and Storage. Information Paper. International Energy Agency, Paris, France.

IMF, 2012. World Economic and Financial Surveys - World Economic Outlook Database. International Monetary Fund (WWW Document). http://www.imf. org/external/pubs/ft/weo/2014/01/weodata/index.aspx

IMPACTE, 1996. Gasoduto de Transporte de Gás Natural-Troço Braga/Tuy (Natura Gas Project-Branch Braga/Tuy). Environmental Impact Assessment no 380. Cibergás. IMPACTE-Ambiente e Desenvolvimento, Lda., Lisbon, Portugal.

IMPACTE, 1997. Gasoduto de Transporte de Gás Natural-Troço Braga/Tuy, Atravessamento do Rio Minho (Natural Gas Project-Branch Braga/Tuy-River Minho Crossing). Environmental Impact Assessment no 465. Cibergás. IMPACTE-Ambiente e Desenvolvimento, Lda., Lisbon, Portugal.

Insight Economics, 2011. Building Essential Infrastructure for Carbon Capture and Storage. Melbourne, Australia.

Interconnector, 2012. The Interconnector (WWW Document). www. interconnector.com

Kanudia, A., Gargiulo, M., Labriet, M., Tosato, G.C., 2012a. Description of the TIMES-COMET Model, an Integrated Energy-CCS Model of Morocco, Portugal and Spain. Technical Note 5.4. Project: Integrated infrastructure for $\mathrm{CO}_{2}$ transport and storage in the west Mediterranean (COMET), Lisbon, Portugal.

Kanudia, A., Gargiulo, M., Labriet, M., Tosato, G.C., Gouveia, J.P., Seixas, J., Fortes, P. Cabal, H., Lechon, Y., van den Broek, M., Carneiro, J., 2012b. Moroccan-Iberian Energy Systems Development Scenarios and Integrated Cost Effective $\mathrm{CO}_{2}$ Source-Transport-Sink Combinations. Technical Note 5.5. Project: Integrated infrastructure for $\mathrm{CO}_{2}$ transport and storage in the west Mediterranean (COMET), Lisbon, Portugal.

Kanudia, A., Gargiulo, M., Labriet, M., Tosato, G.C., Gouveia, J.P., Seixas, J., Fortes, P., Cabal, H., Lechon, Y., van den Broek, M., Carneiro, J., 2012c. Moroccan-Iberian Energy Systems Development Scenarios and Integrated Cost Effective $\mathrm{CO}_{2}$ Source-sink Combinations. Deliverable 5.1. Project: Integrated infrastructure for $\mathrm{CO}_{2}$ transport and storage in the west Mediterranean (COMET), Lisbon, Portugal

Kanudia, A., Gargiulo, M., Labriet, M., Tosato, G.C., Gouveia, J.P., Seixas, J., Fortes, P., Cabal, H., Lechon, Y., van den Broek, M., Carneiro, J., 2012. Moroccan-Iberian energy systems development scenarios and integrated cost effective $\mathrm{CO}_{2}$ source-transport-sink combinations. WP 5 - Technical Note 5.5. Appendix B: Energy and emission tables by scenario. Project: Integrated infrastructure for $\mathrm{CO}_{2}$ transport and storage in the west MEdiTerranean (COMET), Lisbon, Portugal.

Kanudia, A., Berghout, N., Boavida, D., Broek Van Den, M., 2013. CCS infrastructure development scenarios for the integrated Iberian Peninsula and Morocco energy system. In: Energy Procedia. Elsevier, pp. 2645-2656.

Knoope, M.M.J., Ramírez, A., Faaij, A.P.C., 2013. A state-of-the-art review of techno-economic models predicting the costs of $\mathrm{CO}_{2}$ pipeline transport. Int. J. Greenhouse Gas Control 16, 241-270, http://dx.doi.org/10.1016/j.ijggc.2013. 01.005

Knoope, M.M.J., Guijt, W., Ramírez, A., Faaij, A.P.C., 2014a. Improved cost models for optimizing $\mathrm{CO}_{2}$ pipeline configuration for point-to-point pipelines and simple networks. Int. J. Greenhouse Gas Control 22, 25-46, http://dx.doi.org 10.1016/j.ijggc.2013.12.016

Knoope, M.M.J., Raben, I.M.E., Ramírez, A., Spruijt, M.P.N., Faaij, A.P.C., 2014b. The influence of risk mitigation measures on the risks, costs and routing of $\mathrm{CO}_{2}$ pipelines. Int. J. Greenhouse Gas Control 29, 104-124, http://dx.doi.org/10. 1016/j.ijggc.2014.08.001

Koornneef, J., Spruijt, M., Molag, M., Ramírez, A., Turkenburg, W., Faaij, A., 2010. Quantitative risk assessment of $\mathrm{CO}_{2}$ transport by pipelines-A review of uncertainties and their impacts. J. Hazard. Mater. 177, 12-27, http://dx.doi.org 10.1016/j.jhazmat.2009.11.068
MARDF, 2009. Decree-Law no 73/2009-Reserva Agricola Nacional. Ministry of Agriculture, Rural Development and Fisheries, Lisbon, Portugal.

MASESP, 2012. Decree-Law 239/2012-Reserva Ecológica Nacional. Ministry of Agriculture, Sea, Environment and Spatial Planning, Lisbon, Portugal.

Macrory, R., Armeni, C., Clarke, C., Docherty, S., Marel Van Der, E., 2013. SCCS $\mathrm{CO}_{2}$-EOR JIP Legal Status of $\mathrm{CO}_{2}$-Enhanced Oil Recovery. Centre for Law and Environment, Edinburgh, UK.

Martínez, R., Carneiro, J., 2011. Database of $\mathrm{CO}_{2}$ sinks. In: Integrated Infrastructure for $\mathrm{CO}_{2}$ Transport and Storage in the West Mediterranean. COMET, Lisbon, Portugal.

Mesquita, P., Carneiro, J., 2013. Efficient Transport Network and Transport Routes Between Source and Sink Clusters-GIS Methodology and Maps. Deliverable 4.3. Project: Integrated infrastructure for $\mathrm{CO}_{2}$ transport and storage in the west Mediterranean (COMET), Lisbon, Portugal.

Mesquita, P., Marques da Silva, J.R., Carneiro, J., 2013. Definition of Source and Sink Clusters. Deliverable 4.2. Project: Integrated infrastructure for $\mathrm{CO}_{2}$ transport and storage in the west Mediterranean (COMET), Lisbon, Portugal.

Mikunda, T., Haan-kamminga, A., Wolff, J., De, Joode, J., De, Meindertsma, W. Nepveu, M., 2011. CATO2 project WP4.1 Deliverable 04: Transboundary legal issues in CCS: Economics, cross border regulation and financial liability of $\mathrm{CO}$ transport and storage infrastructure. Energy Centre of the Netherlands (ECN) Netherlands Organisation for Applied Scientific Research (KEMA), University of Groningen (RUG), the Netherlands.

Mikunda, T., van Deurzen, J., Seebregts, A., Tetteroo, M., Kersemakers, K., Apeland, S., 2011b. Towards a transport infrastructure for large-scale CCS in Europe. In: D3.3.1 WP3.3 Report Legal, Financial and Organizational Aspects of CO2 Pipeline Infrastructures. Energy Centre of the Netherlands (ECN), Anthony Veder, Gassco, the Netherlands.

Municipality Coimbra, 2010. Warning no 6562/2010-Plano Director Municipal de Coimbra, Coimbra, Portugal

Municipality Lisbon, 2012. Warning no 11622/2012-Plano Director Municipal de Lisboa, Lisbon, Portugal.

NERA Economic Consulting, 2009. Developing a Regulatory Framework for CCS Transportation Infrastructure (Vol. 1 of 2). London, UK.

NERA Economic Consulting, 2009. Developing a Regulatory Framework for CCS Transportation Infrastructure (Vol. 2 of 2): Case Studies Prepared for DECC Project Team, London, UK.

Pöyry/Heymo, 2011. Ceoducto de transporte Compostilla. Documento inicial HEYMO Ingeniería and Pöyry, Madrid, Spain.

PHMSA, 2013. Incident data access. U.S. Department of Transportation. Pipeline \& Hazardous Materials Safety Administration (WWW Document). http://primis phmsa.dot.gov/comm/reports/safety/sida.html?nocache $=8520$

RCI, 2009. $\mathrm{CO}_{2}$ Capture, Transport and Storage in Rotterdam. Report 2009. Rotterdam Climate Initiative (RCI), Rotterdam, the Netherlands

REN, 2007. Infra-estruturas De Gás Natural. Lista E Comprimentos Dos Gasodutos De Transporte E Ramais Industriais Em Alta Pressão. Número De Documento: p-00000-lst-dp-1001 (Natural gas infrastructure). Rede nacional de transporte de gás natural. REN-Redes Energéticas Nacionais, SGPS.

REN, 2013. Natural Gas Transportation Network. Rede nacional de transporte de gás natural. REN-Redes Energéticas Nacionais, SGPS (WWW Document). http://www.ren.pt/

Raine, A., 2008. Transboundary Transportation of $\mathrm{CO}_{2}$ Associated with Carbon Capture and Storage Projects: An Analysis of Issues under International Law, Carbon \& Climate Legal Review 4, 353-365.

Ramírez, A., Brouwer, A.S., Broek Van Den, M., 2011. COMET report D-WP 6: $\mathrm{CO}_{2}$ transport by pipeline-an overview of the current state of knowledge. In: COMET-Integrated Infrastructure for $\mathrm{CO}_{2}$ Transport and Storage in the West Mediterranean. Utrecht University, Utrecht, the Netherlands.

Relvas, S., 2008. Transporte Por Oleoduto E Gestão De Produtos Petrolíferos: O Caso De Portugal (Tranportation by Pipeline and Management of Oil Products: Portuguese Case). Instituto Superior Técnico, Lisbon, Portugal.

Ren Gasodutos, 2007. Leis, regulamentos, códigos e normas aplicáveis decretos-gás natural. Albergaria-a-Velha, Portugal.

Road CCS, 2013. Flow Assurance \& Control Philosophy. Rotterdam Opslag en Afvang Demonstratieproject. Special Report for the Global Carbon Capture and Storage Institute. Maasvlakte CCS Project c.v. Government of the Netherlands, Global CCS Institute.

SEIA, 1994. Projecto de Gás Natural-Gasoduto Setúbal/Braga [Natural Gas Project-gas pipeline Setúbal/Braga]. Environmental Impact Assessment no 140. TRANSGÁS-Sociedade Portuguesa de Gás Natural, SA. SEIA-Sociedade de Engenharia e Inovação Ambiental, S.A., Portugal.

SEIA, 1995a. Projecto de Gás Natural-Gasoduto Setúbal/Braga-Ramal Montemor (Natural Gas Project-gas pipeline Setúbal/Braga-Branch of Montemor). Environmental Impact Assessment no 328. TRANSGÁS-Sociedade Portuguesa de Gás Natural, SA. SEIA-Sociedade de Engenharia e Inovação Ambiental, S.A., Portugal.

SEIA, 1995b. Projecto de Gás Natural-Gasoduto Setúbal/Braga-Ramal Montemor (Natural Gas Project-gas pipeline Setúbal/Braga-Branch of Lisboa). Environmental Impact Assessment no 360. TRANSGÁS-Sociedade Portuguesa de Gás Natural, SA. SEIA-Sociedade de Engenharia e Inovação Ambiental, S.A. Portugal.

SSEB, 2010. A Policy, Legal, and Regulatory Evaluation of the Feasibility of a National Pipeline Infrastructure for the Transport and Storage of Carbon Dioxide. Southern States Energy Board, Norcross, Georgia, US.

Sanders, M., Fuss, S., Engelen, P.-J., 2013. Mobilizing private funds for carbon capture and storage: an exploratory field study in the Netherlands. Int. J. 
Greenhouse Gas Control 19, 595-605, http://dx.doi.org/10.1016/j.ijggc.2013. 09.015

Santos, M., 2011. Estudo do comportamento dinâmico da rede nacional de transporte de gás natural [Study of the dynamic behavior of the natural gas national grid]. In: Thesis. Instituto Superior Técnico, Lisbon, Portugal.

Shogenova, A., Piessens, K., Ivask, J., Shogenov, K., Martínez, R., Flornes, K.M., Poulsen, N.E., Wójcicki, A., Sliaupa, S., Kucharič, L., Dudu, A., Persoglia, S., Holloway, S., Saftic, B., 2013. CCS directive transposition into national laws in Europe: progress and problems by the end of 2011. In: Energy Procedia. Tallinn, Estonia, pp. 7723-7731, http://dx.doi.org/10.1016/j.egypro.2013.06.718

Terwel, B.W., ter Mors, E., Daamen, D.D.L., 2012. It's not only about safety: beliefs and attitudes of 811 local residents regarding a CCS project in Barendrecht. Int. J. Greenhouse Gas Control 9, 41-51, http://dx.doi.org/10.1016/j.ijggc.2012.02. 017

UCL, 2014. Carbon Capture Use and Storage Legal Resource Net (WWW Document). http://decarboni.se/publications/carbon-capture-use-andstorage-legal-resource-net (accessed 05.06.15.).

Van den Broek, M., Ramírez, A., Groenenberg, H., Neele, F., Viebahn, P., Turkenburg W., Faaij, A., 2010. Feasibility of storing $\mathrm{CO}_{2}$ in the Utsira formation as part of a long term Dutch CCS strategy an evaluation based on a GIS/MARKAL toolbox. Ninth Int. Conf. Greenhouse Gas Control Technol. 4, 351-366, http://dx.doi.org/ 10.1016/j.ijggc.2009.09.002

Van den Broek, M., Boavida, D., Cabal, H., Carneiro, J., Fortes, P., Gouveia, J.P.L., Labriet, M., Lechon, Y., Martinez, R., Mesquita, P., Rimi, A., Seixas, J., Tosato, G., Zarhloule, Y., 2013. Integrated infrastructure for $\mathrm{CO}_{2}$ transport and storage in the west Mediterranean-Report with selection of most promising CCS infrastructure options. Technical Note 6.4. Project: Integrated infrastructure for $\mathrm{CO}_{2}$ transport and storage in the west Mediterranean (COMET), Lisbon, Portugal.

Van den Broek, M., Mesquita, P., Carneiro, J., Silva, J.R., Berghout, N., Ramírez, A., Gouveia, J.P., Seixas, J., Cabal, H., Martinez, R., Rimi, A., Zarhloule, Y., Sardinha M., Boavida, D., Tosato, G., 2013b. Region specific challenges of a $\mathrm{CO}_{2}$ pipeline infrastructure in the west mediterranean area model results versus stakeholder views. In: Energy Procedia. Elsevier B.V., Kyoto, Japan, pp. 3137-3146, http://dx.doi.org/10.1016/j.egypro.2013.06.200

Warren, L., 2012. International marine treaty developments 4th IEA International CCS. In: Regulatory Network Meeting Paris 9-10 May 2012, Carbon Capture \& Storage Association, Paris, France.

World Bank, 2011. Carbon Capture and Storage in Developing Countries: A Perspective on Barriers to Deployment. World Bank, Washington, DC, USA.

Wu, Z., Ramírez, A., 2010. Possibilities, Synergies and Conflicts for building a common $\mathrm{CO}_{2}$ pipeline in the North Sea. Report WP 5. Fossil Energy Coalition ERA-NET, Copernicus Institute for Sustainable Development and Innovation Science. Technology and Society Utrecht University, Utrecht the Netherlands.

ZEP, 2013. $\mathrm{CO}_{2}$ Capture and Storage (CCS) in Energy-intensive Industries-An Indispensable Route to an Eu Low-carbon Economy. Zero Emissions Platform (ZEP), Brussels, Belgium. 